\title{
La reforma de la relación de empleo público en Italia
}

Manuel Martínez Bargueño*

Es objeto del presente trabajo el estudio del proceso de transformación del sistema de gestión de personal en Italia, a partir de la Ley núm. 421, de 23 de octubre de 1992, de "Delegación al Gobierno para la racionalización y la revisión de las normativas en materia de sanidad, de empleo público, de previsión y de financiación territorial" (en adelante, L.D./92), publicada en la Gaceta Oficial de 31 de octubre de 1992, completada con el Decreto Legislativo núm. 29, de 3 de febrero de 1993, "sobre la racionalización de la organización de las Administraciones Públicas y revisión de esta normativa por lo que respecta al empleo público en cumplimiento del articulo 2 de la Ley 421/1992, de 23 de octubre" (en adelante, D.L./93), publicado en la Gaceta Oficial de 6 de febrero de $1993^{1}$.

La normativa citada es el estadio terminal de un proceso legislativo ya concluido en sus líneas generales, definitorias del modelo a seguir, al que, sin embargo, le falta un requisito fundamental para su valoración, que es el de ser efectivamente aplicado.

Los comentarios aparecidos en España sobre esta reforma se han limitado a subrayar sus aspectos más llamativos como son la "privatización" de la relación laboral, los nuevos horarios de trabajo o la posibilidad de despido en caso de ineficiencia absoluta².

Sin embargo, la reforma italiana no se limita a la modificación de la naturaleza de la relación de servicio que une a la Administración con los empleados públicos, sino que ésta es sólo una pieza de un engranaje hacia un cambio mayor en el sistema de organización total de la Administración Pública, cambio sentido en Italia como una cuestión "de carácter nacional" y de relevancia decisiva para la supervivencia del sistema políticoinstitucional del que la Administración forma parte.

Para la elaboración de este trabajo hemos utilizado tanto fuentes documentales indirectas de carácter doctrinal, completadas con noticias de prensa, como fuentes directas, deducidas de las presentaciones y posteriores coloquios celebrados en el Seminario sobre "La gestión de personal en la reforma de la Administración Pública", organizado por la Universidad Internacional Menéndez y Pelayo (Sevilla, octubre de 1993) y en las Jornadas de Análisis de Sistemas de Función Pública, organizadas por el Ministerio para las Administraciones Públicas con la colaboración del Instituto Nacional de Administración Pública, la Universidad Carlos III y el Banco Exterior de España (octubrediciembre 1994), una de cuyas ponencias, la relativa al modelo de Función Pública en Italia, correspondió al autor de este artículo.

\section{¿Privatización o contractualización de las relaciones labo- rales?}

En primer lugar, una cuestión semántica, no de tono menor, relativa a lo que es el estandarte de la reforma, esto es, el cambio de naturaleza en la relación de empleo. La doctrina italiana ${ }^{3}$ prefiere la utilización del término privatización para referirse, bien a la homologación formal y sustancial entre empleo público y privado, bien al camino seguido para ello: aplicación al empleo público del principio de autonomía privado, de la legislación civil y de la jurisdicción ordinaria. El término privatización de amplio uso, también, en los medios de comunicación, es rechazado, sin embargo, por los expertos sindicales 4 , impulsores del primer proyecto, que lo estiman impropio, al entender que dicha expresión para que fuera plenamente aceptable requeriría también de la privatización de la Administración Pública empleadora 0 al menos que ésta estuviera obligada a seguir las reglas empresariales privadas en lo referente a su gestión, lo que no sucede así. Por ello, prefieren el empleo del término contractualización, de alcance más limitado, parejo con el de Derecho común, con lo que quieren significar la posición subordinada del empleo público y privado bajo un único régimen confiado en gran parte a la propia negociación colectiva. A veces, los sindicatos utilizan la expresión contractualización plena para enfatizar la doble opción a favor de un contrato de trabajo dependiente como fuente constitutiva y del convenio colectivo de Derecho común como fuente reguladora preferente. A lo largo de este texto utilizaremos indistintamente ambas expresiones -privatización/contractualización-, hecha salvedad de sus diferencias.

\section{Marco de referencia}

Antes de entrar en el comentario sobre el iter legislativo de la reforma, parece conveniente exponer cuáles han sido las circunstancias que han propiciado su lanzamiento, para lo cual trazaremos con carácter previo un marco de referencia. 
Este marco estará determinado por las cinco siguientes cuestiones:

a) Dimensión cuantitativa y cualitativa del empleo público

b) Crisis del modelo tradicional de Función Pública

c) Crisis de la dirigenza pública

d) Crisis de la representatividad de los sindicatos en el empleo público

e) Tendencia doctrinal hacia la convergencia entre relación de empleo público y relación laboral privada.

\section{a) Dimensión cuantitativa y cualitativa del empleo público}

A 31 de diciembre de 1992, el personal funcionario o laboral al servicio de las Administraciones Públicas en Italia era de 3.799.183, distribuidos conforme se señala en el siguiente cuadro (fuente: Tesorería General del Estado, Ministerio de Hacienda. Cuentas anuales 1992).

\begin{tabular}{|c|c|c|c|}
\hline Departamento o sector & De plantilla & No de plantilla & \\
\hline $\begin{array}{l}\text { Ministerios } \\
\text { Administraciones autónomas } \\
\text { Escuela } \\
\text { Universidad } \\
\text { cuerpos de policia } \\
\text { Magistratura } \\
\text { Fuerzas Armadas }{ }^{\text {an }} \\
\text { Entes públicos o económicos } \\
\text { Regiones con estatuto ordina- } \\
\text { rio y autonomías locales } \\
\text { Regiones con estatuto especial } \\
\text { y provincias autónomas } \\
\text { Servicio Sanitario Nacional } \\
\text { Entes de investigación }\end{array}$ & $\begin{array}{l}278.8 / 9 \\
276543 \\
1.003 .174 \\
99.165 \\
279.932 \\
9.280 \\
128.339 \\
68.156 \\
652.016 \\
37.567 \\
661.782 \\
15.103\end{array}$ & $\begin{array}{r}619 \\
14 \\
71.425 \\
207 \\
21.850\end{array}$ & $\begin{array}{r}2.277 \\
26.300 \\
579 \\
15.597 \\
602\end{array}$ \\
\hline Total general & 3.509 .932 & 124.736 & 150.010 \\
\hline \multicolumn{4}{|c|}{$\begin{array}{l}\text { Resumen de los empleados de las Administraciones Públicas a } 31 \text { de } \\
\text { diciembre de } 1992 \text {. } \\
\text { Agentes auxiliares. } \\
\text { Alumnos } \\
\text { * Tropa voluntaria, de reemplazo y alumnos número } 222560\end{array}$} \\
\hline
\end{tabular}

Forman parte de las Administraciones del Estado, en sentido estricto, esto es del personal de los Ministerios, de las Administraciones Autónomas, de la Escuela, de la Universidad, de los Cuerpos de Policía, de las Fuerzas Armadas, de la Magistratura y de la Carrera Diplomática, un total de 2.280 .360 empleados, mientras que el resto (1.518.823) comprende al personal de los Entes públicos no económicos, de las Regiones, de las Autonomías Locales, de los Entes del Servicio sanitario nacional y de las Instituciones de investigación y experimentación 5 .

Este número no es excesivo en relación con la media de los países industrializados $-17,2$, porcentaje del empleo público sobre total de población ocupada frente a la media del 17,7 (OCDE, 1991)-, lo que es más grave es su mala distribución geográfica que acarrea un tradicional desequilibrio entre las oficinas del Norte de Italia, desprovistas de personal y el Sur, sobresaturado 6 . Los desequilibrios son, también, por categorías: sobran profesores y faltan, por ejemplo, enfermeros y personal de limpieza.

Italia es, además, el único país de Europa donde las retribuciones de los funcionarios han crecido por encima de las del sector privado y más que la inflación, siendo superiores a las que obtienen su colegas europeos ${ }^{7}$. Los costes de personal representan aproximadamente los dos tercios de los gastos públicos corrientes y su proyección es aún mayor si se toma en cuenta el denominado "sector público ampliado", desde siempre muy influido por el comportamiento de la Administración Pública.

He aquí, pues, dos primeras razones importantes para la reforma, la necesidad de controlar los costes de personal y favorecer la movilidad geográfica de los empleados públicos.

Pero si importante es la dimensión cuantitativa, aun lo es más el perfil cualitativo del empleado público. A una mayor retribución comparativa, se unen unas condiciones laborales privilegiadas que hacen de la función pública italiana un ámbito protegido, calificado certeramente de "paraíso". Así, el horario de trabajo en la Administración Pública es de 36 horas semanales, frente a las 39 horas del sector privado; el empleado público disfruta de 32 días laborables de vacaciones totalmente retribuidos, más cuatro días adicionales por festividades suprimidas; puede solicitar la excedencia por razón de enfermedad con una duración total de año y medio, retribuida íntegramente durante el primer año y al 50\% durante los seis meses siguientes; disfruta de permisos extraordinarios "por motivos graves", con una duración de dos meses, de los cuales el primero es enteramente retribuido y el segundo al $80 \%$ y, por último, puede jubilarse con tan sólo veinte años de servicios?.

Ciertamente los tópicos sobre un funcionariado indolente, improductivo, devorador del presupuesto del Estado, insensible a los intereses de la comunidad no son una imagen compartida por todos (según la encuesta Formit 1993, el $73^{\prime} 7 \%$ de los italianos reconocía la profesionalidad de los funcionarios y el $70^{\prime} 1 \%$, los juzga además disponibles y corteses), pero estas críticas expresan bien la convicción social de que el funcionariado goza tradicionalmente en Italia de un privilegio legal en lo que respecta a sus retribuciones y condiciones laborales ${ }^{10}$.

El empleo público en Italia tiene, pues, una mala imagen social, tanto más arraigada en cuanto que la Administración es en parte el reflejo de una sociedad cuyas contradicciones reproduce. Dice CASSESE que en Italia todo el mundo se queja de las demoras, de la ineficacia, del bizantinismo y de los formalismos inútiles de una burocracia cuyos disfuncionamientos recaen claramente, de una u otra manera, sobre los ciudadanos que la Administración parece considerar a su servicio y no a la inversa ${ }^{11}$.

Dentro de este mismo contexto hay que introducir también el dato de la competencia internacional. En tal sentido, los empresarios italianos se lamentan de que un bajo nivel de eficacia en el funcionamiento del sector público es un freno para la competitividad del país que juega de manera desfavorable en relación 
con otros países (caso de la transmigración de empresas del Piamonte al Rodano) cuando, además, en toda Europa se está produciendo de forma acelerada una reducción de la protección del sector público, especialmente en aquellos sectores más unidos a servicios de carácter transferible o intercambiable como telecomunicaciones, transportes o energía.

Profesionalizar el empleo público, mejorar la gestión, con pretensiones de modernización, eficiencia y servicio al usuario, son razones esenciales que están dentro del espíritu de la reforma. En palabras de Tiziano Treu, Director de la Agencia para la representación negocial de las Administraciones Públicas: " $l$ desafio es éste: o se tiene éxito en la tarea de mejorar la eficacia y calidad de los servicios públicos o crecerá la presión de la opinión a favor de "privatizar" el empleo público con el riesgo de demoler piezas todavía esenciales de un Estado Social que no se ha sabido renovar" ${ }^{\prime 2}$.

\section{b) Crisis del modelo tradicional de Función Püblica}

Como segunda causa de la reforma debemos señalar la crisis del modelo tradicional de Función Pública, que, como señalan D'OrTA y DiAmanti, se ha debatido históricamente entre dos tendencias contradictorias: de un lado, la indefinición entre un modelo burocrático y un modelo, llamémoslo así, empresarial y, de otro, la difusión de un modelo único de Función Pública versus la proliferación de modelos especiales diferenciados ${ }^{13}$.

El modelo burocrático y la concepción centralizada de la Función Pública italiana alcanzan su apogeo en 1957 (D.P.R. no 3/1957). En este texto ordenador del empleo estatal se reconoce la figura clásica del empleado público que personifica la soberanía del Estado y se halla unido al mismo por una relación de sujeción, gozando de un estatuto privilegiado. Coherente con esta visión clásica, el funcionario recibe prerrogativas y honores y se halla sometido a una jurisdicción especial. Este texto de 1957 que no ha sido sustituido por completo a pesar de las reformas posteriores, constituye, por así decirlo, la "Biblia" del empleado público tradicional.

Esta representación burocrática y monolítica de la Función Pública entra en crisis en los años setenta y principios de los ochenta. La Ley marco nำ 93/83 supone, a estos efectos, un claro cambio de rumbo: se abandona el sistema jerarquizado de carrerás y se adopta un sistema de ordenación de los empleados públicos sobre la base de perfiles profesionales y cualificaciones funcionales, inspirado parcialmente en modelos privados introduciéndose principios rectores del sistema que afectan a la igualdad de retribuciones para los empleados pertenecientes a una misma cualificación funcional, a la movilidad entre Administraciones, a los procedimientos de selección, a la formación, a la responsabilidad y a los derechos sindicales. A la vez, la Administración Pública quedaba "compartimentizada" en grandes áreas (Ministerios, administraciones de Hacienda, empresas públicas de carácter no comercial e industrial, entes de investigación, escuela, sanidad, regiones y entidades locales) a fin de que cada uno de estos compartimentos tuviera, en el marco de estos principios generales, una legislación homogénea y adaptada a sus propias peculiaridades.
Infortunadamente las esperanzas depositadas en esta reforma se vieron pronto frustradas. La aplicación de la Ley 93/83 chocó con una realidad fuertemente fragmentada y cruzada por tensiones de signo diverso: "al lado de la bomologación formal referida a un modelo sustancialmente unitario de la materia de la relación de empleo del personal al servicio de las Administraciones Públicas, ban aparecido tendencias centrifugas de diversa naturaleza, parcialmente idóneas para estimular procesos de diferenciación interna" (Ruscino, 1978).

Lo más grave es que estas tendencias centrifugas no han nacido conectadas a exigencias debidas a la articulación de nuevos modelos organizativos por razón de la creciente multiplicidad y heterogeneidad de los distintos sectores de actuación de las Administraciones Públicas, sino que tales quiebras al modelo homogéneo han sido la respuesta dada por grupos o sectores que han determinado fugas o sustracciones al régimen general en una continuada carrera para alcanzar posiciones de ventaja competitiva, eso sí, sin poner en cuestión el tranquilizador paraguas protector de la disciplina unitaria del empleo público, dando lugar a la exacerbación de los conocidos fenómenos de las junglas normativa y retributiva, características de la Función Pública italiana ${ }^{14}$.

En el transcurso de los últimos años, el impulso reivindicativo, encabezado por aquellos ámbitos y sectores con una fuerte presencia de profesiones tradicionales, ha querido asegurarse en el empleo público un status, una organización autónoma, alimentada por una renta diferencial, con la complicidad de un empleador público pensando más en términos de consenso electoral que en criterios de racionalidad y productividad económica. Sucede así que el empleo público ha ganado la partida al empleo privado, desembocando en una especie de tándem privilegiado formado por una mayor estabilidad y una retribución más alta en comparación con el sector privado.

Habida cuenta de esta situación se comprende que sea objetivo de la reforma aproximar lo más posible las reglas y prácticas de gestión pública con las del empleo privado, tenidas de entrada por más flexibles y eficientes, terminando con la profusa reglamentación de carácter rígido y estratificado y fijando mecanismos que garanticen un grado de relación entre retribuciones, coste de la vida y calidad del servicio prestado.

\section{c) Crisis de la "dirigenza" pública}

La Administración Pública italiana, al igual que una pirámide truncada -dice Sabino CASSESE- se halla falta de una auténtica alta función pública. Los dos proyectos habidos para crear unas élites administrativas, semejantes a las que existen en Francia o Gran Bretaña, acabaron en sendos fracasos, tanto la auspiciada por Francesco Saverio MITTI, ministro de la época de GIOLITT, como la más reciente en los años setenta, merecedora de algunos comentarios.

El D.P.R. número 748 , de 30 de junio de 1972, intentó separar dirección política y actividad administrativa mediante la institución de la dirección pública (dirigenza estatale), por escisión del tronco superior de la carrera administrativa, articulándola en tres niveles jerárquicamente ordenados: primer dirigente superior y 
dirigente general, a los que se unían algunas cualificaciones específicas tales como prefectos de primera clase en la Administración del interior, ministros plenipotenciarios y embajadores en la Administración en el exterior y directores generales en las empresas autónomas del Estado.

Se pretendía con esta dirigenza configurar un cuerpo de colaboradores del vértice político, dotado de competencias propias y autónomas. A tal efecto, se atribuyeron a cada uno de estos niveles directivos, en el marco de los programas y prioridades definidas por el ministro, competencias precisas de dirección de oficinas (o de inspección o de estudio) y poderes de negociación por cuenta y nombre de la Administración (para las materias y dentro de los límites establecidos por la ley).

Correspondiente a estos poderes se estableció una responsabilidad precisa de los dirigentes por los resultados, previéndose que los ministros no podrían actuar sobre atribuciones conferidas a aquéllos sino mediante actos formales de anulación, avocación o reforma de las medidas adoptadas, o para categorías limitadas de actos, mediante procedimientos explícitos de reserva o de avocación de materias.

La dirigenza se benefició de un estatuto particular y de unas remuneraciones bastante elevadas. Sin embargo, el modelo no funcionó por defectos intrínsecos de la reforma (techos cuantificados de gastos demasiado bajos y pronto erosionados por la inflación, exclusión de determinadas categorías de actos), por la persistencia del modelo jerárquico y, en último extremo, por las resistencias encontradas entre la propia clase dirigente.

Además el acceso a la dirigenza estuvo abierto con generosidad durante largo tiempo ${ }^{15}$. No se debiera haber contado con más de 1.500 personas, pero, a principios de la década de los noventa, su número oscilaba entre los 7.000 y los 8.000 .

La creación de la dirección pública no se vio acompañada, tampoco, de la reorganización de los Ministerios y los gabinetes de los ministros acabaron por ocupar el espacio que les dejaron los dirigentes. Como dice D'ALBERTI: "los bombres del Ministro ban echado fuera a los bombres del Ministerio, causándoles no pocas frustraciones" 16 .

En definitiva, hacia finales de los años 70 y principios de los 80, la tentativa de modernizar la Administración estatal mediante la reforma de la dirección pública aparecía como un rotundo fracaso.

d) Crisis de la representatividad de los sindicatos en el empleo público

En Italia, los sindicatos son los más fuertes y representativos de Europa. Su influencia en el sector público ha ido en aumento desde los años setenta, en los que la negociación sindical fue progresivamente reconocida mediante leyes particulares como fuente de valor reglamentario para ciertos aspectos de la Función Pública, si bien con notables diferencias sectoriales en cuanto a las materias a negociar (sólo retribuciones o incluidos algunos aspectos del estatuto normativo) y sobre los procedimientos.
La Ley marco de 1983 vino a fijar unas condiciones uniformes en cuanto a la negociación colectiva para el conjunto de la Función Pública. Se distinguió entre materias objeto de regulación unilateral, y materias objeto de negociación (retribuciones), junto a aquellas otras en las que confluían ambas fuentes, la norma unilateral para fijar principios generales y la negociación para los detalles. Se definieron también tres niveles de negociación: intersectorial, para todas aquellas cuestiones a reglamentar de forma idéntica en todo el ámbito de la Función Pública, sectorial, para las remuneraciones y, descentralizado, para todos los demás asuntos. Se reguló, asimismo, el proceso de negociación cuyo resultado final -el convenio colectivo de trabajodebía ser sancionado formalmente por un Decreto del Presidente de la República.

Este marco unitario hacía concebible la apertura de un clima de cooperación intensa entre las grandes centrales sindicales: CGIL (comunista), CISL (democracia cristiana) y UIL (socialista) con el Gobierno; sin embargo, no se contó con la explosión en los siguientes años de la presencia del sindicalismo autónomo y de las instancias corporativas que arruinaron en la práctica el papel representativo que debiera haber jugado el sindicalismo confederal.

En los últimos años, este sindicalismo confederal, que cuenta con una elevada tasa de sindicalización tanto absoluta como relativa a nivel nacional, ha pagado un precio cada vez más alto por la caída de la representación-representatividad en el ámbito del empleo público; de aquí que para solucionar la situación de privilegio en un área protegida y estanca como es el empleo público que sustrae directa o indirectamente recursos al empleo privado, la tríplice confederal (CGIL-CISL-UIL) haya visto como única terapia posible la privatización de la relación de empleo.

e) Tendencia doctrinal bacia la convergencia de la relación de empleo público y la relación laboral privada.

Dice CASSESE que lo que ha motivado que la ciencia jurídica y la jurisprudencia mantuvieran incólume la teoría del empleo público como netamente distinta a la del privado ha sido, de una parte, preocupaciones ideológicas y culturales y, de otra, exigencias prácticas.

El primer elemento lo constituía la dificultad de entender paritarias unas relaciones Administración-funcionario que conferían a éste, una vez nombrado, la titularidad de potestades públicas. Otra explicación, ésta de carácter práctico, es que cuando esta relación de empleo en las Administraciones Públicas se desarrolla, la regulación legal de la relación de trabajo privada era embrionaria por lo que la rica disciplina legislativa del empleo público suponía una diferencia importante entre ambos tipos de relación laboral.

Estas premisas -señala CASSESE- han cambiado actualmente. Ante todo ha cambiado la posición constitucional del ciudadano respecto del poder público. En segundo lugar, los empleados públicos han crecido en número y se han diversificado (en Italia hay 285 perfiles y figuras profesionales solamente entre los funcionarios públicos estatales) y, en tercer lugar, se ha afirmado, especialmente a partir de la Ley marco 93/83, la negociación 
colectiva de las condiciones económicas y de trabajo de los empleados públicos.

El proceso doctrinal tendente a finalizar en la convergencia entre relación de empleo público y relación laboral privada, parte de la distinción en el Estatuto del Empleado Público de dos elementos diferentes que tradicionalmente se han considerado unidos formando una sola cosa: uno, de carácter organizativo y, otro, de carácter personal. Si consideramos ahora que los caracteres propios del primer elemento (funciones, poderes) no se transmiten traslativamente a la persona, podríamos reformularnos la pregunta de si los caracteres distintivos de la regulación de empleo en la Admininistración Pública son diversos de la relación laboral privada.

Puede argumentarse -concluye CASSESE- que el elemento distintivo fundamental del empleo público estriba en la circunstancia de que la materia de personal (selección, nombramiento, subordinación, causas modificativas o extintivas de la relación) se halla regulado por ley o por otro instrumento normativo, pero no por ello puede decirse que la relación de empleo público sea distinta de la del privado, porque aquí también será una regulación legal de las mismas materias, aunque con distinta extensión, motivada por la necesidad de proteger el trabajo dependiente, motivación que es tan intensa en el área pública como en la privada y que, por tanto, ha producido resultados que no son diferentes.

\section{Antecedentes de la reforma}

La reforma del empleo público en Italia es el resultado de una evolución que comienza en la segunda mitad de los años 70 , a lo largo de la cual se sucedieron, en breve lapso de tiempo, la ponencia CoPpo (1977), el dictamen CNeL (1978), y el informe GianNIN (1979), los cuales crearon el caldo de cultivo necesario para la incubación de la Ley marco núm. 93/1983.

La principal preocupación de la Ley marco 93/1983 fue, como su propio nombre indica, proporcionar un marco homogéneo de principios jurídicos y de criterios objetivos válidos para todo el sector del empleo público, pero sin afectar a la naturaleza de la relación, esto es, manteniendo el modelo público, caracterizado por la naturaleza de supremacía especial en la relación y por el sometimiento de conflictos en materia de empleo público a una jurisdicción separada.

La gran novedad de la Ley marco 93/1983 consistirá en colocar en el sistema de fuentes y al lado de la Ley, al convenio colectivo, aunque éste último sin caracter autónomo, en cuanto que sus contenidos no adquieren fuerza obligatoria hasta tanto no se recojan en decretos presidenciales.

Sistema de fuentes, tachado por Carinci de sofisticado $y$ barroco, al distribuir las materias entre Ley y convenio colectivo, a veces de forma diferenciada, a veces concurrente, prever una negociación con alma negocial y cuerpo reglamentista y configurar una secuencia rígida formada por la negociación del convenio, autorización para firmarlo, recepción en decretos presidenciales y control a posteriori del Tribunal de Cuentas. Por eso, dice este autor que la Ley marco puede considerarse como un híbrido entre lo público y lo privado, entre la conservación del status del empleado y la contractualización de su régimen económico-normativo.

Lo cierto es que la Ley marco 1983, demasiado rígida en abstracto y demasiado manejable en concreto, puesta en relación con una realidad fuertemente atormentada como la del empleo público, en esos años tuvo una vida agitada y dolorosa. De hecho, los últimos años 80 fueron testigo de una creciente "indigestión de la ley", manifestada a través de "una salvaje competencia entre las fuentes que provocaba una copiosa legislación, unos convenios más políticos que sindicales, ausentes en ocasiones del control contable y recibido siempre con un gran retraso, una administración de personal definida a menudo en términos consociativos y una jurisprudencia administrativa inducida a jugar al alza" 17 .

La crisis de la Ley marco 83 adquiere rasgos patológicos con los fenómenos ya señalados de huída de la propia ley por parte de sectores y ámbitos de la Administración Pública, debida al impulso reivindicativo de colectivos y grupos deseosos de lograr posiciones de ventaja y obtener una "renta diferencial" en el empleo público.

El panorama legislativo surgido tras la aplicación de la Ley ha supuesto una reglamentación de la relación de trabajo emanada de fuentes contractuales y fuentes legislativas alimentadas por un Parlamento que se ha perdido en la elaboración de pequeñas leyes sobre aspectos menores de la situación jurídica y del régimen retributivo de los empleados.

Paralelamente se produce una crisis en la representación/representatividad de los sindicatos confederales, incapaces de justificar ante sus bases nacionales la existencia de un sector público que recibe un mejor trato que el sector privado. No es de extrañar, por tanto, que la primera respuesta a la crisis del modelo sea una respuesta sindical, deseosa de reconciliar ambos mundos, público y privado, de forma que los tratamientos económicos fueran equivalentes en uno y otro.

\section{Cronologia de la reforma}

El primer proyecto fue protagonizado por CGIL y a él se unieron rápidamente CISL y UIL, mediante un proyecto unitario destinado a servir de referente a la posterior evolución. Esta propuesta de la tríplice confederal se basa desde el primer momento en la privatización de la relación de empleo, pero sin que tal privatización proyectada afectara a los órganos y entes administrativos, lo que suscitó críticas y reservas en medios económicos y jurídicos.

Con fecha 7 de febrero de 1991, se celebró en el Palacio Chigi una reunión en la que participaron el Vicepresidente del Consejo de Ministros del Gobierno Andreotti, Claudio Martelli, los Ministros Remo Gaspari, Ciorino Pomicino y Guido Carli y las cúpulas de la CGIL, CISL y UIL. El encuentro concluyó con un entendimiento "político" sobre la exigencia de superar la Ley marco sobre el empleo público.

Como resultado de esta reunión se formó una comisión mixta de juristas sindicales y expertos nombrados por el Gobier- 
no, encargada de "verificar la viabilidad técnico jurídica de la bipótesis de contractualización plena del empleo público", cuya actividad finalizó en abril de 1991 con la entrega de un borrador de proyecto articulado.

En diciembre de 1991 se produce una aceleración del proceso, tras una reunión entre el Gobierno y los agentes sindicales y en la cual el Gobierno "asume el compromiso con las Confederaciones sindicales de poner en marcha antes del 10 de enero de 1992 el Proyecto de Ley que contenga nuevas normas en materia de relación de empleo". Promesa mantenida, aun con un ligero retraso, dado que el Consejo de Ministros aprueba el 16 de enero un borrador de proyecto de ley y el 27 de febrero un proyecto de ley que contiene "nuevas normas en materia de relación de trabajo y de empleo asi como de convenios colectivos de los empleados públicos".

Sucede, sin embargo, que este proyecto de ley emana de un Gobierno predimisionario y que se envía a un Parlamento en trance de disolución, por lo que con tales circunstancias el futuro del proyecto se presentaba nebuloso, máxime cuando el único dato probable, en vísperas electorales, era que el próximo Gobierno fuera aún más débil y el Parlamento estuviera todavía más fragmentado, condiciones nada favorables para el nacimiento de una reforma tan comprometida como la del empleo público.

El futuro inmediato vino a confirmar este dato pero también a desvirtuar sus efectos, porque en el nuevo Gobierno Amato surgido de las urnas, el factor económico acaba por compensar su relativa fragilidad política, debido a la incidencia de la dramática coyuntura económica.

Ello explica la ulterior aceleración del proceso contenida en el protocolo de 6 de junio de 1992. En ese momento la reforma pasa a ser menos sindical y más gubernativa, deja de ser una alternativa propiciada por los sindicatos y pasa a ser considerada como una partida del propio Gobierno destinada a ser incluida en una operación más amplia que vincula el empleo público, sanidad, pensiones, privatizaciones de empresas, etc. De esta forma, una intervención radical con reorganización de la Administración Pública, centralizada sobre un elemento puntual -la naturaleza de la relación de trabajo-, se configura en una pieza clave para la contención del gasto público y el saneamiento económico del país.

La inclusión de la privatización en la gran maniobra financiera de 1993 constituye una garantía para su aprobación, estando la propia supervivencia del Gobierno condicionada a la entrada en vigor de la Ley lo que conlleva un doble riesgo que se advierte en su redacción definitiva: una aceleración de los tiempos técnico-políticos de tramitación y una atención obsesiva por la normativa general de control y la particular de contención de costes.

En el transcurso de poco más de cuatro meses, el proyecto de ley cumple su itinerario parlamentario iniciado en el Senado el 14 de julio, prosigue en la Cámara con la devolución al Senado de un texto notablemente modificado y finaliza con la redacción definitiva como Ley núm. 421, de 23 de octubre de 1992.
En poco más de tres meses, tiempo reglamentario prefijado, ve la luz el Decreto legislativo de 3 de febrero de 1993, que define y completa el marco conceptual mediante un amplio repertorio de artículos que hacen referencia a sucesivas disposiciones reglamentarias, ya de por sí expresivas de un claro intento deslegalizador $^{18}$.

Como subraya Lisso (Sevilla, 93) la reforma es el resultado de un acuerdo con una doble mira: el de las Confederaciones sindicales que han visto la posibilidad de realizar una negociación más libre en un sector hasta ahora protegido y la del Gobierno que quiere ahorros en el sector público para reducir la relación entre PIB y deuda global (con el más fuerte endeudamiento de Europa, el $116 \%$, según la OCDE) y contener el crecimiento del déficit público.

\section{Contenido de la reforma}

\section{Sistema de fuentes}

Una cuestión importante conviene retener al principio de esta exposición: que, a partir de la reforma de 1992/93, las relaciones de trabajo y de empleo de los empleados públicos en Italia se han "privatizado", esto es:

a) se regulan mediante contratos individuales y convenios colectivos

"que las relaciones de trabajo y de empleo de los empleados de la Administración del Estado y de los otros Entes... sean reguladas mediante contratos individuales y convenios colectivos" (art. 2.1 a) L.D. 92).

b) se reconducen bajo la disciplina del Derecho civil y de las leyes laborales

"(que) sean reguladas por las disposiciones de las secciones II y III, Capítulo I, Tîtulo II, del Libro V del Código Civil y por las lejes sobre relaciones de trabajo subordinado en la empresa en todo lo compatible con la especialidad de la relación y con el objetivo de los intereses generales en los términos definidos en el presente Decreto" (art. 2.2 D.L 93), así como específicamente a la Ley 300/1970, de 20 de mayo (Estatuto de los Trabajadores) que "se aplica a las Administraciones Públicas con independencia del número de empleados" (art. 55.2 D.L.93)

c) que, como consecuencia de lo anterior, se produce un cambio de jurisdicción de todas las controversias referentes a la relación de trabajo de los empleados de las Administraciones Públicas del juez administrativo al juez o magistrado de lo social (artículo 68. D.L.), si bien este cambio no será efectivo hasta pasados tres años.

La aparente simplicidad de la reforma se ve complicada no obstante por dos cuestiones: la extensión del área sometida a la privatización con relación tanto al ámbito objetivo como subjetivo de la reforma y, de otra parte, a la propia intensidad de esta sujeción, en lo que respecta a la reserva de ley sobre determinadas materias, debido a la especialidad de la relación y al respeto 
al objetivo de los intereses generales, condiciones ambas expresamente señaladas en el artículo 2.2 D.L. 93.

De aquí que la doctrina italiana subraye el carácter disociado del actual sistema de fuentes de la relación de empleo público que incluye no sólo a las mencionadas: convenio colectivo, Código Civil y normativa general, sino también, y en las materias correspondientes, a la ley, al reglamento y a los actos de organización vinculados o no a normativa previa.

\section{Ambito objetivo}

A tenor de lo expresado en la nueva normativa, podemos distinguir entre:

Administraciones sometidas a una aplicación integral de la normativa en toda la Administración del Estado, incluidos los "institutos y escuelas de cada orden y grado y las instituciones educativas, las empresas y Administraciones del Estado en régimen autónomo... las provincias, los municipios, las comunidades montañesas, y sus consorcios y asociaciones, las instituciones universitarias, los institutos autónomos de protección popular, las cámaras de comercio, industrias, artesania y agricultura y sus asociaciones, todos los entes públicos no económicos nacionales... y locales y las Administraciones, las empresas y los entes del servicio sanitario nacional' (artículo 1.2 D.L. 93).

Administraciones no sometidas a una aplicación íntegra de la normativa. A su vez, se pueden distinguir:

- Las Regiones con estatuto ordinario para las cuales "las disposiciones del presente Decreto constituyen principios fundamentales en los términos del artículo 117 de la Constitución", a las cuales se atendrán teniendo en cuenta "las peculiaridades de sus respectivos ordenamientos" (artículo 1.3 D.L. 93).

- Las Regiones con estatuto especial y las provincias autónomas de Trento y Bolzano para las cuales los principios de la reforma constituyen "normas fundamentales de reforma económico social de la República" (artículo 1.3 D.L. 93).

- Las empresas y los entes ya fugados de la Ley marco, bien porque hayan sido sometidos con anterioridad a un sistema contractual de reglamentación de las relaciones de trabajo o porque tengan un sistema diferente respecto de la Ley marco. Entre éstos se encuentran, por ejemplo, los entes autónomos líricos y las instituciones concertísticas, la Agencia Espacial Italiana, el Instituto Poligráfico y la Casa de la Moneda del Estado, la RAI, el Instituto Nacional para el Comercio Exterior, etc., todos los cuales deben adecuar los propios ordenamientos a los principios generales de la reforma" (artículo 73.5 D.L. 93).

\section{Ambito subjetivo}

Aquí la reforma ha operado utilizando a priori criterios funcionales en razón del sector de pertenencia para incluir o excluir del ámbito de su aplicación a las distintas categorías.
Las categorías excluídas, tanto de la "contractualización" de las relaciones de trabajo y empleo como de la aplicación de la normativa privada, están perfectamente definidas en el artículo 2.4 del D.L. 93 y son las siguientes: "los magistrados ordinarios, de lo administrativo y lo económico, los abogados y procuradores del Estado, el personal militar y de las fuerzas de policia, el personal perteneciente a la carrera diplomática a partir de la categoría de secretario de legación, el personal de prefectura, a partir de la categoria de viceconsejero, los directores generales nombra: dos por Decreto del Presidente de la República, previa deliberación del Consejo de Ministros y equiparados a los mismos y los secretarios municipales y provinciales, excepto para estos últimos en lo que se refiere a las remuneraciones que serán definidas en los convenios colectivos según el articulo 73.3 D.L. 93".

Para los profesores e investigadores se ha dado una solución temporal: mantenimiento de su statu quo hasta 1.6.94, fecha a partir de la cual se les aplicará el Decreto, salvo que antes de esta fecha sea aprobada "la normativa específica que regule, de modo armónico, su relación de empleo de acuerdo con los principios de autonomía universitaria" (artículo 72.4 D.L. 93), caso curioso de delegación inversa mediante la cual el reglamentador reenvía al legislador, según anota CARINCI.

El criterio diferenciador utilizado para la exclusión de estas categorías nọ ha sido en todo caso el del ejercicio de funciones públicas, como testimonia el dato de que hayan resultado "privatizados" los dirigentes (salvo los dirigentes generales), no obstante reconocerles funciones públicas (artículo 17 D.L. 93), más bien el criterio diferenciador hay que buscarlo en el particular papel que desempeñan (diplomáticos y prefectos), al peculiar vínculo de subordinación (militares y fuerza de policía) o a su posición de autonomía con respecto a la Administración (magistrados) y que caracteriza a las distintas relaciones jurídicas.

De todas formas, los criterios no están del todo claros y las exclusiones prefijadas pueden constituir, a juicio de la doctrina, una especie de juego anticipado que preludie la marcha de otros sectores interesados en no permanecer mucho tiempo en el campo de fuerza de la nueva disciplina ${ }^{19}$.

Las categorías incluidas -el resto de los empleados que entran de lleno en la "contractualización de la relación de empleo""componen un complejo de figuras y profesiones que ocupan un amplio espectro corporativo de las Administraciones Públicas, de los Ministerios, de las Autonomias Locales, de los entes paraestatales a las empresas autónomas, del sistema escolar al servicio sanitario nacional" (CORSO) ${ }^{20}$. La novedad más revolucionaria está en la inclusión de la segunda clase de dirigentes, categoría estratégica dentro de la reforma y que fue el resultado de una "fatigosa fórmula de compromiso" (CARINCI), compensada, como veremos, con la creación de una disciplina autónoma sobre la materia. 


\section{Reserva de ley}

La definición de los ámbitos objetivo y subjetivo a los que se aplica la reforma es sólo una premisa, puesto que tales ámbitos no han sido "privatizados" totalmente. Hay una parte, más o menos amplia, que queda fuera cubierta por la reserva de ley, con el sentido y efectos del artículo 97 de la Constitución italiana que establece una reserva de ley en materia de organización de servicios públicos.

Para la determinación de la zona cubierta por la reserva de ley debemos volver al análisis del artículo 2.1 de la L.D. 92, cuya declaración de intenciones y objetivos ha de gravitar -como dice CARINCI- sobre la futura interpretación doctrinal y jurisprudencial.

Según este artículo fundamental de la L.D. 92, el Gobierno queda apoderado para que, en un plazo brevísimo de noventa días, apruebe o publique uno o varios decretos legislativos orientados "a la contención, a la racionalización y al control de los gastos para el sector del empleo público, al mejoramiento de la eficacia y de la productividad, asi como a su reorganización". Obsérvese cómo el primer lugar en la redacción de este artículo lo ocupa la preocupación por el gasto en el sector público (contención-racionalización-control) y sólo en segundo lugar se menciona el binomio eficacia-productividad, lo que permite apreciar perfectamente el significado del golpe de timón gubernamental sobre el primer proyecto de la Confederación sindical, si bien es cierto que en la redacción del D.L. 93 vuelve a primer plano la finalidad de "aumentar la eficacia de las Administraciones", mientras que "racionalizar el costo del empleo público" se menciona en segundo lugar (artículo 1.1 D.L. 93).

Volviendo a la redacción del artículo 2.1 de la L.D. 92, su apartado a) fija una importante fórmula de salvaguarda: los decretos delegados emanados del Gobierno deberán prever que las relaciones de trabajo y de empleo de los empleados de las Administraciones del Estado y de los entes se reconduzcan bajo la disciplina del Derecho civil y sean reguladas mediante contratos individuales y convenios colectivos "salvo los limites relacionados con la consecución de los intereses generales a los que se dirigen la organización y la actividad de las Administraciones Públicas".

Por su parte, el artículo 2.2 del D.L. 93 completa esta fórmula de salvaguarda señalando que "las relaciones de trabajo de los empleados de las Administraciones Públicas están reguladas por las disposiciones... del Código Civil y por las leyes sobre relaciones de trabajo subordinado en la empresa en todo lo compatible con la especialidad de la relación y con el objetivo de los intereses generales en los términos definidos en el presente Decreto".

Entiende la doctrina, al interpretar estos artículos, que los intereses generales no son indeterminados sino precisamente los definidos en el D.L. 93, que apuesta claramente por la capacidad privada de la Administración Pública, la cual actúa en las mate- rias sujetas a la normativa del Código Civil, leyes laborales y contratos colectivos "con las competencias del empresario privado, adoptando todas las medidas inberentes a la organización y a la gestión de las relaciones de trabajo" (artículo 4.1 D.L. 93).

Resulta así una doble capacidad de los sujetos públicos: pública y privada. Éstos intervienen con capacidad pública en temas organizativos, mientras que actúan con capacidad privada en lo que se refiere a la celebración de los convenios y a la gestión de la relación de empleo.

Hecha salvedad de esta fórmula de salvaguarda, interpretada en el sentido regulado por la norma e indicada por la derogación de la normativa privatista expresamente señalada, estas derogaciones vienen señaladas en el larguísimo artículo $2.1 \mathrm{c}$ ) de la L.D. 92, el cual establece un elenco de temas, muchos de ellos traídos del artículo 3 de la Ley Marco 83, a los que se aplica la reserva de ley: "serán regulados por ley o bien con base en la ley o en el ámbito de sus principios fijados por actos normativos o administrativos las siguientes materias":

- los órganos, los puestos de trabajo, las formas de atribuir la titularidad de los mismos c)2

- los principios fundamentales de organización de los puestos de trabajo c)3

- los procedimientos de selección para el acceso al trabajo y la preparación para el mismo c) 4

- las plantillas y dotaciones orgánicas, aunque con el compromiso, antes de determinar su dotación total, de informar previamente a los sindicatos más representativos a nivel nacional c) 5

- las incompatibilidades y responsabilidades c)1 y c)7

- la garantía de la libertad de enseñanza e investigación c)6.

La doctrina señala que este elenco del artículo $2.1 \mathrm{c}$ ) es más reducido que el del artículo 2 de la Ley marco 83, de lo que parece desprenderse una cierta expansión del área de negociación colectiva, pero esto no es del todo así, porque de un lado la negociación colectiva puede no obtener el éxito apetecido y, en tal caso, la Administración recobra su libertad de acción y puede proceder unilateralmente con respeto de las garantías sociales y situaciones individuales $y$, de otro, porque fuera de esta relación de materias se encuentra la lista completa de criterios y principios directivos que conforman, como veremos a continuación, una disciplina autónoma dentro de la reforma.

\section{Directivos (dirigenza)}

Una de las ideas clave de la reforma, frente a las dificultades del erario público y a la progresiva degradación de los servicios públicos, es que una distinción nítida entre los planos de dirección política y administrativa, que suponga una valoración decisiva de la autonomía de los directivos, constituye instrumento esencial para el cambio. 
La doctrina se ha apresurado a confirmar este aserto: "punto esencial para el éxito de la reforma es la plena responsabilización de los dirigentes en sus tareas gestoras y por tanto la separación entre politica y gestión, de lo que es presupuesto" (TREU); "se trata de una figura central que constituye el punto de contacto $e$ intercambio entre lógica pública y privada" (CARINCI); "La reforma apuesta bacia una estilización de la dirección pública en función de una gestión administrativa más dinámica, moderna y atenta a la calidad y al resultado" (CoRso), opiniones que son también compartidas por los líderes sindicales, coimpulsores de la reforma: "nosotros vemos en la figura del dirigente el núcleo central sobre el cual ba de recaer el éxito ofracaso del nuevo sistema" (FocILL, UIL).

Ciertamente, la reforma no carecía de antecedentes: aparte del intento frustrado del D.P.R. número 748, de 30 de junio de 1972 , ya comentado, un primer paso se dio por la Ley número 88 , de 9 de marzo de 1989, que reestructuró los dos mayores entes del Paraestado: INPS e INAIL; otro segundo se efectuó por Ley número 142, de 8 de junio de 1990, sobre dirigentes de los entes locales y un tercer intento reformador operó, respecto al servicio sanitario nacional, mediante Decreto-Ley número 35, de febrero de 1991, completado por el Decreto Legislativo número 502 , de 30 de diciembre de 1992. Por eso, se puede decir que la reforma de la dirigenza pública en el D.L. 93 no es sino el último anillo del proceso en orden a revalorizar la dirección pública en Italia.

El carácter central que reviste la cuestión directiva en el contexto de la reforma es inmediatamente perceptible, pues buena parte del texto del D.L. 93 está ocupado por disposiciones sobre organización y normas relativas a materias de dirigenza pública.

Dos son los objetivos que persigue la reforma: en primer lugar y, con caracter fundamental, reforzar la autonomía de la dirigenza frente al poder político, dejando a los dirigentes un ámbito propio de actuación, libre de las injerencias de los políticos aunque condicionado a que la función directiva se desarrolle conforme a los objetivos y siguiendo las directrices definidas por los órganos políticos. El segundo objetivo es extender el principio anterior de "distinción" entre esfera política y gestión directiva a todas las Administraciones Públicas, no sólo para mejorar la eficiencia de todas y cada una de ellas sino también para favorecer la formación de una clase directiva cultural y funcionalmente más homogénea y unitaria, dentro de la cual sea posible que exista una cierta movilidad.

El principio fundamental manifestado expresamente en la L.D. 92, en base al cual el D.L. 93 regula de manera precisa esta materia es el de la distinción entre tareas de dirección política y tareas de dirección administrativa. Así, el artículo 3 del D.L. 93 distingue las tareas atribuidas a los órganos políticos de las propias de los órganos administrativos, diciendo "Los órganos de dirección politica definen los objetivos y los programas de actua- ción y verifican la conformidad de los resultados de la gestión administrativa con las directrices generales impartidas. A los dirigentes les corresponde la gestión financiera, técnica y administrativa, incluida la adopción de todos los actos que comprometan a la Administración hacia el exterior mediante poderes autónomos de gasto, de organización y de los recursos bumanos $e$ instrumentales y de control. Son responsables de la gestion asi como de los correspondientes resultados" 21 .

A este propósito dice D'OrTa que la relación entre órganos de dirección política y dirigentes, hasta ahora encuadrada en un sistema sustancialmente jerárquico, asume muy claramente las connotaciones de una relación de dirección, esto es, de una forma de supraordenación distinta, por calidad e intensidad, que la propia de la jerarquía. Paralelamente se acentúa la tendencia a transformar a la dirigenza pública en management, abandonando el modelo burocrático tradicional (los directivos custodios de la legítima ejecución administrativa) con ventaja para un modelo de dirección más empresarial (los directivos como gestores de los recursos de la Administración y como responsables de los resultados $)^{22}$.

A decir verdad la línea de demarcación entre política y administración queda un tanto difuminada con la reintroducción final, en el proceso de elaboración del Decreto, delegado de un poder de avocación del Ministerio sobre los actos de competencia directiva (artículo 14.3 D.L.), por motivos excepcionales de necesidad y urgencia ${ }^{23}$.

Otra novedad de la reforma es el carácter generalizado que se quiere dar a la materia, sobre dirección pública, no restringida a sectores específicos de la Administración. Esto ha levantado muchas críticas, entre ellas la del propio CASSESE ${ }^{24}$. Así se ha dicho que el D.L. 93 pretendía generalizar un modelo de relación política-administración y un diseño de dirigenza pública concebido pensando exclusivamente en los Ministerios ${ }^{25}$.

En el cuerpo de la reforma, la figura del dirigente se articula en dos categorias: el del dirigente general y el de dirigente. La distinción entre ellos es bastante clara. El dirigente general es el que actúa de modo más inmediato y directo al lado de los órganos políticos y por ello se encuentra más controlado y condicionado. Por esta misma causa se ve excluido de la contractualización en lo que se refiere a sus retribuciones y a los restantes perfiles de reglamentación de la relación. En cambio, el dirigente, incluido en la contractualización de su relación laboral, adquiere un mayor despliegue de competencias, así, por ejemplo, en materia del personal a su cargo, los dirigentes pueden trasladar a los empleados de unos puestos de trabajo a otros e incluso ponerles en situación de movilidad (collocamento in mobilitá) en caso de rendimiento insuficiente o cuando exista personal sobrante (artículo 17.1 D.L. 93).

Las particularidades de la regulación de su relación de trabajo y empleo son las siguientes: 
- En materia de nombramiento, los dirigentes generales son nombrados por Decreto del Presidente de la República, previa deliberación del Consejo de Ministros y a propuesta del Ministro competente entre "sujetos que tengan la profesionalidad adecuada a las funciones a desempeñar, con categoria de dirigente de la Administración o de otras Administraciones, o bien procedente de organismos o entes públicos o empresas públicas y privadas con experiencia adquirida de al menos cinco años en cargos directivos, o bien de los sectores de investigación y docencia universitaria, de la judicatura y de la abogacia del Estado"(artículo 21 D.L. 93). Por tanto, el nombramiento de dirigente general puede recaer no sólo en directivos públicos sino también en personas ajenas a la Administración Pública, con tal de que estén en posesión de los requisitos señalados para ser nombrados dirigente general. Los nombramientos deben ser comunicados al Parlamento, adjuntando un currículum relativo a los títulos y experiencia profesional de los nombrados.

En cambio, para acceder a la categoría de dirigente el artículo 28 del D.L. 93 señala dos métodos: el primero requiere la superación de una oposición con examen, convocada por las distintas Administraciones, a la cual pueden ser admitidos los empleados de carrera de las Administraciones que estén en posesión del diploma de licenciatura y que ya pertenezcan a la ex- carrera directiva. También pueden ser admitidos a esta oposición aquellos que hayan sido ya aprobados por oposición con examen en categorías funcionales correspondientes y que hayan permanecido por lo menos cinco años de servicio efectivo en la categoría.

El segundo método prevé el acceso a la categoría de dirigente de aquellos empleados que hayan asistido y superado un curso-oposición (corso-concorso) en la Escuela Superior de la Administración Pública ${ }^{26}$.

Con el primer método se pretende reclutar el $70 \%$ de los dirigentes y con el segundo el 30\% restante.

- En materia de remuneraciones, éstos quedan sujetos a los incrementos en razón a las exigencias del servicio.

- En materia de responsabilidad, los directores generales y los dirigentes "son responsables del resultado de la actividad desarrollada en los departamentos en los que se encuentren, de la ejecución de los proyectos y programas a ellos confiados, de la gestión del personal y de los recursos financieros e instrumentales que se les ba asignado"(artículo 20.1 D.L. 93). En esta materia de responsabilidad la preocupación por los resultados, una de las "obsesiones" de la reforma, se ve remarcada mediante un sistema de evaluación y control que incluye la presentación a principios de año por parte de los dirigentes al dirigente general y de éstos al Ministro, de un informe sobre la actividad desarrollada durante el año precedente (artículo 20.1 D.L. 93), la evaluación de resultados a cargo de "núcleos de valoración" o "servicios de control interno" (artículo 20.2 D.L. 93) de los costes de los puestos de trabajo (artículo 18.1 D.L. 93) y el establecimiento de sanciones en caso de obtención de malos resultados en la gestión, que puede comportar la "puesta a disposición" por el período máximo de un año con la consiguiente pérdida del régimen económico complementario conectado con las funcionès (artículo 20.4)

El dato de mayor interés es que la evaluación del trabajo de los dirigentes se refiere a la gestión global encaminada a la consecución de un objetivo y no como conjunto de actos individuales. Los dirigentes cesan de responder al órgano político por cada acto singular y devienen responsables por el resultado global de sus propias decisiones y por la observancia de las directrices político-administrativas.

- De manera más general, en materia de actuaciones operativas y de gestión, se confiere a los dirigentes una autonomía de poderes decisionales en sus relaciones con los interlocutores sindicales, los cuales devienen en destinatarios de informaciones y sujetos de consultas, pero que, sin embargo, no deben obstaculizar ni paralizar la solución autónoma de decisiones y medidas que son competencia del dirigente.

A la figura profesional de los dirigentes, que es la que conserva el influjo de un mayor régimen "público", le viene confiada por la reforma la tarea de gestionar los aparatos administrativos, según lógicas "privatistas" y manageriales, aunque en la práctica tal cuestión queda abierta, confiada a la capacidad de la clase política y de los propios dirigentes para actuar según las nuevas reglas de juego. Así, por ejemplo, el artículo 14 D.L. 93 prevé que, pasados dos meses desde la aprobación del presupuesto, el órgano político, una vez definidas las metas político administrativas, asignará a las oficinas de nivel más elevado y con base en sus respectivas funciones y dotaciones de personal e instrumentales, las correspondientes cuotas partes del presupuesto. De este modo, los dirigentes pueden disponer del horizonte financiero necesario para organizar racionalmente las decisiones de gestión en una lógica, plenamente empresarial, de presupuesto objetivo.

Señala CARINci cómo la virtualidad de la reforma dependerá de cómo se realice la determinación de los puestos de trabajo de nivel directivo, que en la Administración del Estado viene establecida mediante reglamento gubernativo (artículo 6.1 L.D. 93) y de que éste se haga a la medida de las exigencias reales de la Administración y no de los intereses del personal directivo que sea necesario colocar ${ }^{29}$, así como de la formación de una nueva clase directiva joven y dinámica, capaz de aunar la cultura burocrática del pasado y la nueva filosofía gerencial inherente a la reforma.

\section{Movilidad y selección}

En línea con el objetivo general de aumentar la eficacia de la Administración y racionalizar el coste del empleo público (artícu- 
lo 1.1 D.L. 93), la normativa de la reforma dispone que, una vez definidos los puestos de trabajo y las plantillas orgánicas, las Administraciones Públicas se ocuparán "de la óptima distribución de los recursos bumanos mediante la coordinación de los procesos de movilidad y selección de personal" (artículo 30.1 D.L. 93).

Movilidad y selección son, pues, dos cuestiones muy conexas en cuanto que hasta que no se hayan realizado las operaciones de definición de funciones y puestos de trabajo y aprobado las plantillas orgánicas no será posible el acceso de nuevo personal.

\section{Movilidad}

Dice Corso que una de las muestras más significativas de la reciente reforma es la particular atención dada al problema de la movilidad de los empleados públicos, con el fin de racionalizar los recursos humanos, previendo una utilización de aquellos empleados que resultaran sobrantes por exceso.

En efecto, con el D.L. 93 se introduce el instituto de la movilidad en el campo del empleo público, a excepción del personal investigador, tecnológico y técnico especializado de las instituciones y entes de investigación y experimentación, al cual no se aplican estas disposiciones ${ }^{30}$.

La introducción de la movilidad ha creado en Italia perplejidad y alarma entre los empleados públicos preocupados porque con la movilidad no se dé entrada en el campo del empleo público al fantasma del despido. Algunos comentarios señalan, no obstante, que el exceso de personal es una hipótesis poco realista, dado que son las propias Administraciones quienes deben determinar el número de su personal en exceso en relación con sus necesidades funcionales, por lo que el despido aparece reducido sólo a aquellos casos más graves, ya contemplados en la anterior normativa ${ }^{31}$.

El procedimiento de la movilidad es bastante complejo y requiere, según el D.L. 93, de la intervención de una pluralidad de organismos.

En primer lugar, es necesario que cada Administración Pública elabore para cada oficina, y previa reunión con los representantes sindicales, la plantilla orgánica de su personal teniendo en cuenta las funciones y los objetivos a conseguir mediante su actividad administrativa. Esta definición de funciones y fijación de plantillas tiene un carácter dinámico por lo que debe ser actualizada cada tres años (artículo 30.2 D.L. 93).

Es en esta materia y en concreto sobre los procedimientos de reestructuraciones orgánicas, análisis de cargas de trabajo, definición de plantillas, etc., donde se han volcado numerosas críticas a la labor reglamentaria llevada a cabo por el Departamento de Función Pública (Directiva nº 77, de 2 de abril de 1994, sobre funciones y plantillas). REBORA considera que la instrumentación adoptada ofrece niveles inútiles de complicación, orientándose hacia criterios exclusivamente cuantitativos, no estimula reestructuraciones incisivas, provoca reacciones defensivas en las Admi- nistraciones Públicas y reproduce en la relación entre Administración del Estado y Administraciones autónomas mecanismos de centralización planificada que no favorecen una clara y transparente responsabilización de los diversos centros de decisión ${ }^{32}$.

Una vez definidas las funciones mediante reglamento gubernativo y aprobadas las plantillas orgánicas del personal mediante Decreto del Presidente del Consejo de Ministros, a propuesta del Ministro competente y con el acuerdo del Ministro del Tesoro y del Departamento de Función Pública, las Administraciones Públicas deben comunicar a la Presidencia del Consejo de Ministros -Ministerio de Función Pública- la composición de su personal, acompañada de una lista nominativa de empleados pertenecientes a las cualificaciones y categorías que presentan excedentes en relación con las necesidades.

Lo más significativo del procedimiento de movilidad, según ha quedado definido en disposiciones reglamentarias es que el Departamento de Función Pública ha de publicar una convocatoria de movilidad en relación con los puestos disponibles en las distintas Administraciones. En esta convocatoria pueden tomar parte tanto los empleados sobrantes como aquellos otros que deseen moverse voluntariamente, con la diferencia de que el personal sobrante que no haya alcanzado destino o rehusado el obtenido, puede ser trasladado de oficio a puestos residuales no cubiertos, aun con cambio de oficina.

El personal en movilidad que no acepte el traslado queda puesto a disposición, en los términos del Titulo VI, capítulo II del DPR de 10 de enero de 1957 (artículo 34.1 D.L. 93).

Conviene precisar, por último, que la movilidad de los empleados públicos, voluntaria o de oficio, puede ser realizada también mediante acuerdo entre Administraciones Públicas y organizaciones sindicales con el consentimiento de los empleados afectados (artículo 18.8 del Decreto Legislativo núm. 546, de 23.12.1993).

\section{Selección}

Hasta tanto no se haya realizado la determinación de las plantillas orgánicas no está permitido el acceso de nuevo personal a las Administraciones Públicas (artículo 31.6 D.L. 93) ${ }^{33}$.

El legislador ha mantenido dentro del esquema público (articulo 1c)4) L.D. 92) el acceso a los empleos en la Administración Pública que se produce normalmente por cuatro vías:

1. Por oposición pública que puede hacerse: a) mediante exámenes; b) por concurso de méritos; c) por concurso-oposición (artículo 36.1 a) D.L. 93).

2. Por selección mediante el desarrollo de pruebas específicas para la comprobación de la profesionalidad requerida (artículo 36.1 a) D.L. 93).

3. Mediante llamada de los inscritos en las listas de empleo de las oficinas de empleo para aquellas categorías y perfiles en 
los cuales se pide solamente el requisito de la enseñanza obligatoria (artículo 36.1 b) D.L. 93).

4. Mediante llamada por orden numérico de los inscritos en las listas especiales de empleo formadas por los pertenecientes a las denominadas "categorías protegidas" (huérfanos, inválidos, etc.) de la Ley número 482, de 2 de abril de 1968.

Carinci sostiene la posición de que el fin constitucional de selección imparcial del personal más idóneo (artículo 97.3 de la Constitución) podría también haber quedado cumplido mediante la aplicación de un sistema de selección privado, pero aquí la inercia del pasado ha resultado muy fuerte por lo que este tema ha quedado inserto en la reserva de ley (artículo 2c) 4) L.D. 92).

A propósito de las oposiciones (concorsi) son antiguas las quejas sobre la falta de criterios objetivos y de transparencia de las mismas: tribunales parciales que incluyen a personas que nada tienen que ver con las materias objeto de examen, proliferación de recomendaciones, falta de garantías para la selección de los mejores, etc.

El asunto adquirió transcendencia constitucional en virtud de dos Sentencias de la Corte Constitucional, números 435, de 15 de octubre de 1990, y 333, de 23 de julio de 1993, que desautorizaron muchas normas especiales, sobre todo de las Administraciones regional, local y autónomas o sectoriales que autorizaban la presencia de representantes políticos o sindicales en las comisiones de selección.

Para sentar reglas de objetividad e imparcialidad, el artículo 6 del Decreto Legislativo número 546, de 23 de diciembre de 1993, prescribe que las comisiones juzgadoras de las oposiciones deben estar formadas por personas que tengan competencia probada en las materias de examen, escogidas entre funcionarios de la Administración o docentes, ajenos a la Administración que convoca la oposición, que no sean miembros de los órganos políticos, que no ocupen cargos de esta naturaleza y que no sean representantes sindicales o nombrados por las Confederaciones y organizaciones sindicales o por las asociaciones profesionales. Además, el apartado 21 del artículo 3 de la Ley número 537, de 21 de diciembre de 1993, prescribe que "las pruebas de examen deben permitir la adecuada verificación de la capacidad y de las aptitudes".

Con respecto a la realización de las oposiciones públicas, el D.L. 93 hace algunas indicaciones en el sentido de racionalizar los costes y reducir los tiempos de celebración: así, impone a las Administraciones Públicas -con la excepción de las Regiones, entes locales, servicio sanitario nacional e instituciones universitarias y de investigación- que se realicen oposiciones únicas, convocadas por la Presidencia del Consejo de Ministros, -Departamento de la Función Pública- (artículo 38.1 D.L. 93) ) $^{34}$.

El D.L. 93 contiene la descripción del procedimiento para llevar a cabo las oposiciones únicas y que es semejante a la fórmu- la española: aprobación por la Presidencia del Consejo, previa información a las Confederaciones Sindicales más representativas de ámbito nacional, fija el número de puestos que deben ser convocados por categorias profesionales y con los destinos a cubrir por quienes superen las respectivas oposiciones únicas (artículo 38.1 D.L. 93). Posteriormente, la Presidencia del Consejo -Departamento de Función Pública- procede a anunciar y llevar a término las oposiciones únicas nombrando en sus respectivos destinos a los aprobados.

El artículo 43.2 D.L. 93 impone a los así nombrados la permanencia en el primer destino por un período de tiempo no inferior a siete años, durante el cual no podrán ocupar puestos de mando o responsabilidad en lugares que ya tengan completa su plantilla en lo que respecta a su categoría. Para ocupar plaza en aquellos lugares donde existan vacantes de su categoría en plantilla, se precisa del consentimiento del directivo de la sede donde pertenezca el empleado.

A estas formas "normales de selección" habría que unir aquellas otras extraordinarias que permiten establecer relaciones laborales y de empleo a tiempo determinado y que se contemplan expresamente, aún con algunas limitaciones, en el D.L. 93.

- Contratos de personal a tiempo parcial (artículo 36.3 D.L. 93), por un año, prorrogable excepcionalmente a dos, para la realización de proyectos específicos con objetivos encaminados a hacer frente a ineficacias administrativas en algunos sectores: lucha contra la evasión fiscal, pensiones, catastro, tutela de bienes culturales y ambientales, protección civil, etc. Estos contratos no pueden interesar a más del $20 \%$ de las dotaciones orgánicas del personal a largo plazo para cada uno de los perfiles profesionales.

- Período bianual de formación y trabajo destinado a los jóvenes entre 18 y 29 años, parcialmente retribuido y que según Corso puede ser entendido como una forma de previsión de una particular modalidad de acceso a la relación de empleo con la Administración Pública caracterizada por un período inicial de contenido formativo (artículo 44 D.L. 93).

\section{La variación de tareas}

Suele ser frecuente en Italia que en muchas oficinas, sobre todo en pequeños municipios o servicios periféricos estatales de dimensiones mínimas, los empleados, debido a la existencia de vacantes en plantilla, sean asignados casi siempre de hecho a desarrollar otras tareas además de las propias de su cualificación funcional $\mathrm{o}$, incluso, exclusivamente tareas de superior cualificación.

El desempeño de estas tareas (mansioni) por vía de hecho y durante largos períodos de tiempo ha dado lugar a una importante polémica por parte de los empleados públicos que reclamaban bien su clasificación en un nivel funcional superior, bien la correspondiente contraprestación económica, pretensiones 
ambas que han sido negadas sistemáticamente por los Tribunales de Justicia hasta que una Sentencia de la Corte Constitucional 9/23.2.1989, al examinar el caso de un radiólogo que desempeñaba de hecho funciones superiores, estableció el criterio de que transcurrido el límite temporal de 60 días, la prolongación de tal situación supone para el empleador un enriquecimiento injusto, lo que determina la obligación de completar las retribuciones del empleado en la medida correspondiente a la calidad del trabajo efectuado.

El D.L. 93 ha venido a resolver esta espinosa cuestión permitiendo a la Administración Pública utilizar una cierta "flexibilidad" al encomendar a los empleados determinadas funciones.

Así, el artículo 56.1 del D.L. 93 sienta el principio general de que el empleado "debe ser destinado a las tareas propias de la categoria a que pertenezca", añadiendo a continuación que en el desempeño de estas tareas entra también "el desarrollo de las competencias complementarias e instrumentales para la consecución de los objetivos de trabajo". El mismo artículo 56.2 señala que "el empleado puede ser destinado a desarrollar algunas tareas especificas de la categoria superior u ocasionalmente y donde sea posible con criterios de rotación, tareas inmediatamente inferiores, si asi se lo pide el dirigente de la unidad organizativa a la que pertenece sin que ello comporte variación alguna en el régimen retributivo".

Hasta aquí el "redondeo de tareas" dentro del margen del contenido profesional del trabajo del empleado. Cosa distinta es la variación vertical de tareas en sentido ascendente, sobre las que el artículo 57.1 D.L. 93 establece la previsión de que "se pueden asignar tareas superiores a los empleados por un periodo no superior a tres meses", si bien esta medida debe ser justificada por el dirigente de la unidad orgánica en la que preste servicios el empleado y sólo bajo unas hipótesis taxativas: "para suplir vacantes en los puestos de plantilla cuya provisión debe ser inmediatamente anunciada o para sustituir a otro empleado ausente con reserva de puesto, excluido el periodo de servicio ordinario, siempre que asi lo exija el servicio". En ambos casos, el empleado se beneficia de la remuneración económica correspondiente, pero, como aclara el artículo 57.2 D.L. 93, "el ejercicio temporal de tareas superiores no atribuye el derecho a la asignación definitiva de las mismas".

Vemos, pues, que a diferencia de las relaciones de empleo privadas, donde el empresario puede variar las tareas del empleado, asignándole funciones equivalentes o superiores, en el sector público y en virtud de una derogación expresa de la normativa privatista, este mecanismo no funciona de manera automática sino que tal promoción sólo se puede conseguir mediante "los procedimientos de cobertura de vacantes" a que alude el artículo 57.3 D.L. 93.

Apunta la doctrina como las previsiones de los artículos 56 y 57 D.L. 93 no permiten al empleado público rechazar la enco- mienda de tareas distintas, lo que sí se le permite al empleado privado por el juego de la legislación privatista (artículo 1460 en relación con el artículo $2103 \mathrm{Cc})^{35}$.

\section{Horario de servicio y jornada laboral}

Una de las causas de mayor descrédito de la burocracia italiana ante la opinión pública, se encuentra en el horario de trabajo de los empleados públicos. "No sólo es que el número de boras semanales (36) sea inferior a las del sector privado (39), sino que además el borario está mal organizado por lo cual las boras de apertura al público son tanto más insuficientes cuanto más se necesitan los servicios del ente" (TREu ${ }^{36}$.

La reforma entiende que esta materia es cuestión íntimamente unida a la de "principios fundamentales de organización de las oficinas" y, por tanto, cubierta por la reserva de ley (artículo 2 c)3 L.D. 92). En desarrollo de la misma, el D.L. 93 distingue entre "borario de servicio", "borario de apertura y cierre al público" y "borario de trabajo", señalando en su artículo 5.1 d) D.L.93 que los tres deben armonizarse "con las necesidades de los usuarios y con los borarios de las Administraciones Públicas de los países de la Comunidad Europea y no sólo del sector privado".

Como norma el horario de servicio se fija en seis días, de los cuales cinco tendrán también horario de tarde, con interrupción de una hora (artículo 60.1 D.L. 93). La determinación del horario de apertura y cierre al público es competencia del dirigente general, pudiendo ser adecuado a la realidad territorial específica por el dirigente previa consulta en ambos casos con las organizaciones sindicales (artículos 16.2 y 17.2 D.L. 93). En cuanto a la jornada laboral, el D.L. 93 parece distinguir entre su duración y su articulación con el horario de servicio. La duración debe ser objeto de convenio y deriva, por tanto, en obligación contractual para el empleado; su articulación, por el contrario, es competencia del director general, previa consulta con las organizaciones representativas (artículo 16 D.L. 93). A este respecto dice CARINCI que parece difícil que el convenio colectivo se limite a la duración de la jornada laboral y en fijar criterios sobre la articulación con el horario de servicio y que, de todas formas, a falta de acuerdo final, toda esta materia retornaría a la competencia de los dirigentes que la regularán, valiéndose de sus poderes como managers privados ${ }^{37}$.

\section{Finalización de la relación laboral}

Señala CARINCI cómo, a falta de una disposición general en la reforma sobre despido de los empleados públicos, se aplica la normativa civil contenida en el Estatuto de los Trabajadores con independencia del tamaño de la Administración (artículo 55.2 D.L. 93).

En este régimen privatista se insertan, no obstante, algunos restos del régimen público preexistente por lo que respecta a dos instituciones: el artículo 58 D.L. 93 regula los casos de incompatibilidades y prohibición de acumulación de cargos, 
remitiéndose a la normativa anterior que, en caso de infracción, contempla la pérdida del empleo.

Otra institución sobreviviente es la puesta a disposición (messa in disponibilitá) que consiste en la separación del servicio por un período no superior a los dos años con derecho a percibir las asignaciones por familia con la exclusión de indemnización y compensación por servicios y prestaciones de carácter especial y por prestación de trabajos extraordinarios. Esta institución de la puesta a disposición opera en dos casos: para los dirigentes generales y dirigentes cuando no hayan seguido las instrucciones recibidas o los resultados de su gestión fueran negativos (artículo 20.4 D.L. 93) y para los empleados cuando rehúsen el traslado de oficio (artículo 34.1 D.L. 93).

\section{El convenio colectivo: planteamiento doctrinal}

Pieza central de la reforma, el nuevo convenio colectivo dice Carinci- constituye una solución de compromiso entre la tradición histórica de los convenios colectivos, recibidos en actos administrativos para materias concretas y regulados en la ley marco de 1983 y las nuevas formas de reparto de la materia de empleo público entre un régimen público y un régimen privado.

Desde el punto de vista político, los nuevos convenios son el resultado de un acuerdo Gobierno-Confederaciones Sindicales mediante el cual la Administración Pública recupera un campo mayor de maniobra en la organización de las oficinas, con base en una mayor deslegalización de la materia y de una más incisiva actuación como empleador público, mientras que las Confederaciones Sindicales mantienen y refuerzan su papel de interlocutor privilegiado.

Según la nueva configuración de la reforma, el convenio colectivo ya no es como en la Ley marco 83, un instrumento de cogestión en las materias determinadas por la ley; por el contrario, en la nueva reforma la negociación es libre y se puede negociar sobre una generalidad de materias referidas a la relación de trabajo, con la única condición de que ambas partes estén de acuerdo en su utilidad.

La doctrina destaca que los nuevos convenios colectivos suponen también un cambio de óptica fundamental que implica un esfuerzo de adaptación por parte de la Administración y Sindicatos llamados a colaborar en el futuro de forma conjunta y eficiente en la negociación de los convenios. Mediante el convenio colectivo, los interlocutores sociales salen reafirmados en sus papeles y se impide la invasión de la Administración por los políticos, una de las mayores lacras del sistema que ha contribuído al clima de corrupción imperante (tangentópolis) y que ha acarreado el descrédito y caída de la Primera República.

La distribución de los recursos económicos también puede contribuir a ese cambio de calidad en la negociación. Hoy, por razones presupuestarias, queda poco espacio para la nego- ciación "adquisitiva"; en cambio, pueden abrirse nuevos espacios de interés común para empleados y Administración como son la mejora de la calidad y la eficiencia de la Administración.

No obstante estas buenas intenciones (baremos convenios virtuosos, dicen los Sindicatos), se percibe cierta desconfianza sobre el nuevo sistema debido a causas diversas: falta de tradición en la negociación libre, dificultad en la coyuntura económica, peligro de repetición de errores y retrasos que han caracterizado a la negociación colectiva en el pasado. Según Treu "O se tiene éxito en bacer de la negociación un instrumento útil, aunque no único, para mejorar la calidad de los servicios públicos y reducir su coste o la reforma del empleo público quedará frustrada desde su momento inicial" 38 .

\section{El convenio colectivo: análisis legal}

El artículo 45 D.L. establece el principio general de que "la negociación colectiva es nacional y descentralizada" y se desarrolla "sobre todas las materias relativas a la relación de empleo", con excepción de las reservadas a la ley, a los actos normativos y administrativos (artículo 2.1 a) L.D. 92).

En esta redacción se adivina ya lo que es el objeto de la reforma, hacer convenios colectivos "de Derecho común", si bien esta pretensión privatista se ve sujeta a un doble condicionamiento constitucional y político: el necesario control del Tribunal de Cuentas sobre los actos del Gobierno que comporten gastos y la representación de las partes en el convenio colectivo. La primera cuestión es resuelta brillantemente mediante la fórmula de la "previa autorización del Gobierno" a suscribir los convenios marco negociados por parte de la Agencia para las Relaciones Sindicales, autorización que está sometida al control del Tribunal de Cuentas "el cual verifica la legitimidad y la compatibilidad económica" durante un plazo de quince días, el mismo que tiene el Gobierno para pronunciarse en sentido positivo o negativo (artículo 51.1 y 2 D.L. 93). Transcurrido dicho plazo y obtenida de forma expresa o tácita la autorización solicitada, se pueden firmar los convenios.

La segunda exigencia, relativa a la representación de las partes en los convenios colectivos, ha sido resuelta asignando a la Agencia para la representación negocial de las Administraciones Públicas la representación "obligatoria" de todas las Administraciones Públicas (2.1. b) D.L. 92 y 50.2 L.D. 93) y obligando a éstas a garantizar a sus propios empleados igualdad de régimen general y, en cualquier caso, regímenes no inferiores a aquellos previstos en los convenios colectivos (artículo 2.1. d) L.D. 92 y 49.2 D.L. 93).

Niveles de negociación y organizaciones sindicales más representativas

El sistema de negociación se caracteriza por su elevado grado de centralización y confederalización, sin duda debido a 
la "berencia del inmediato pasado" (CARINCI) y al interés compartido por el Gobierno y los sindicatos de mantener un rígido control sobre todo el proceso negocial.

Básicamente la estructura del convenio sigue descansando sobre los tres niveles tradicionales de la Ley marco 1982: los convenios colectivos "marco", mediante los cuales pueden ser regulados de manera uniforme para todos los sectores y áreas de negociación "la duración de los convenios colectivos y materias especificas de cada uno" (artículo 45.5 D.L. 93); los convenios colectivos "nacionales" que "se estipulan por centros de la Administración Pública, comprendiendo sectores bomogéneos 0 afines" (artículo 45.2 D.L. 93) y la "negociación descentralizada", "destinada a la atemperación entre necesidades organizativas, la tutela de los empleados y los intereses de los usuarios" y que se desarrolla "sobre las materias y en los limites establecidos por los convenios colectivos nacionales" (artículo 45.4 D.L. 93) ${ }^{39}$.

La segmentación vertical por ámbitos de negociación -ocho, según el D.P.R. número 68 de 1986: de los Ministerios, del paraestado, de las Regiones y de los entes locales, de las empresas autónomas, de la sanidad, de los entes de investigación, de la escuela y de la universidad- ha sido retomada por el D.L. 93, si bien en una versión más dúctil, previéndose su posible modificación (artículo 45.3 D.L. 93), sin que sea necesario estipular un único acuerdo para cada uno de estos entes, lo que según Corso "puede ser leido como una potencial apertura de nuevos espacios para la afirmación de la diversidad de la materia, coberente con las características y exigencias de los variados contextos operativos".

Esta estructura sigue administrándose en base a un criterio de legitimación rígido, en cascada de las organizaciones sindicales: las Confederaciones más representativas a nivel nacional para los convenios colectivos marco (artículo 45.6 D.L. 93); las mismas, más las organizaciones más representativas a nivel nacional en el ámbito sectorial para los convenios colectivos nacionales (artículo 45.7 D.L. 93) y para los convenios colectivos descentralizados "una representación compuesta según la modalidad definida por el convenio colectivo nacional" (artículo 45.8 D.L. 93).

La mayor representatividad en el ámbito nacional de las Confederaciones y de las organizaciones sindicales se remite a un futuro acuerdo entre el Presidente del Consejo de Ministros y las Confederaciones Sindicales, recogido posteriormente en Decreto del Presidente de la República, previa delegación del Consejo de Ministros (artículo 47.1 D.L. 93)

Como fórmula de compromiso y para la dirigenza pública, se ha previsto en la reforma un área de negociación separada y autónoma, distinta para cada ámbito sectorial. Resulta así un área convencional separada tanto en vertical como horizontal, visto que para cada ámbito sectorial se debe negociar un acuerdo específico para la dirigenza. El único lazo de unión resulta de la representación formada, de un lado, por la Agencia para la representación negocial de las Administraciones Públicas y, de otro, por las Confederaciones Sindicales más representativas a nivel nacional, pero se trata -dice CARINCI- de una representación equívoca porque las Confederaciones no representan verdaderamente a los dirigentes y en cuanto a la Agencia ésta se halla condicionada por los datos que recaba de los propios dirigentes.

En cuanto a las materias a negociar en esta área separada éstas son muy restringidas, pues la determinación de los puestos de trabajo y de las funciones corresponde a la autoridad competente mediante reglamento (artículo 2.1 c) L.2 92 y 6 D.L. 93) al igual que la gradación del régimen retributivo de los complementos (artículo 24.1 D.L. 93).

Agencia para la representación negocial de las Administraciones Públicas

Como señala la doctrina, la creación de la Agencia para la representación negocial de las Administraciones Públicas supone un salto cualitativo de enorme importancia con respecto a etapas precedentes en cuanto confía la negociación colectiva centralizada y por áreas o sectores a un organismo técnico especializado, despolitizando la gestión de los convenios colectivos.

En efecto, bajo la Ley marco de 1983, las negociaciones estaban atribuidas por parte pública a los Ministerios de la Función Pública, del Tesoro, del Presupuesto, del Trabajo y a otros sujetos seleccionados en función de la representatividad de las Administraciones y de los entes involucrados en la negociación, con lo que el carácter político de ésta parecía indudable. Ahora, después de la reforma, mientras la composición de la delegación pública aparece inalterada en la negociación descentralizada, para los ámbitos superiores aparece un organismo específico, la Agencia para la representación negocial de las Administraciones Públicas que, según el artículo 50 D.L. 93, representa a nivel nacional en sede de contratación colectiva a todas las Administraciones Públicas.

La Agencia para la representación negocial de las Administraciones Públicas (en adelante, Agencia) fue creada por el artículo 2.1 b) L.D. 92 y 50.1 D.L. 93, modificado por el Decreto Legislativo "correctivo" número 470, de 10 de noviembre de 1993. Su reglamento orgánico y de funcionamiento ha sido aprobado por DPR número 144, de 25 de enero de 1954.

La Agencia está dotada de personalidad jurídica y de autonomía organizativa, gestora y contable, y depende de la Presidencia del Consejo de Ministros, a través del Ministerio de Función Pública. Está regida por un Comité Directivo de cinco miembros, escogidos entre expertos de reconocida competencia en materia de relaciones sindicales y de gestión de personal nombrados por el Presidente del Consejo de Ministros, previa deliberación de éste y que representan tres al Gobierno y dos a las Regiones y municipios, y a los entes locales, respectivamente ${ }^{40}$. Está previsto que el Comité Directivo elija entre sus componentes al Presidente de la Agencia. 
La Agencia tiene también un Comité de Coordinación de catorce miembros, formado por representantes de las áreas o sectores que actúan en los distintos ámbitos de la contratación colectiva. El personal de la Agencia, que tiene su sede en Roma, está formado mayoritariamente por funcionarios, de los cuales una quinta parte proviene de las Regiones; también puede recibir colaboraciones de personas ajenas a la Función Pública a las que encargue trabajos a tiempo total o parcial.

La tecnicidad o especialidad de la Agencia no implica su funcionamiento al margen del Gobierno que asume el papel de representar a los intereses de las diversas Administraciones en la contratación colectiva, tanto generales como sectoriales. Por eso, la Agencia debe atenerse en la negociación colectiva a las directrices que le imparta el Consejo de Ministros, previo acuerdo con las Administraciones Regionales manifestado en la Conferencia de los Presidentes de las Regiones para el personal dependiente de éstas y de los entes regionales y previo "parecer" de las provincias y de los ayuntamientos para el personal dependiente respectivo. Estas directrices se refieren a los "criterios generales sobre materia contractual..., criterios sobre la atribución, en sede de contratación descentralizada, de conceptos retributivos... estándares de rendimiento y de resultados y los criterios para verificarlos" (artículo 50 D.L. 93)

Consecuentemente, la capacidad negociadora de la Agencia aparece doblemente limitada por las disponibilidades financieras y por las directrices recibidas del Gobierno.

Queda por decir, únicamente, que en sede de negociación descentralizada la Agencia puede ser solicitada a desarrollar una actividad de representación y de asistencia a las Administraciones Públicas, quedando éstas vinculadas en todo caso a prestar conformidad a las directrices recibidas de la Agencia, función que ha sido criticada por la doctrina al entender que altera el equilibrio de poderes entre nivel central y nivel local ${ }^{42}$.

\section{Procedimiento de negociación}

A diferencia de lo que sucedía en la Ley marco de 1983 no hay en la reforma actual del empleo público un procedimiento de negociación definido. Anteriormente, la negociación colectiva formaba parte de un procedimiento administrativo que diluía la función de la contratación colectiva y que, de otra parte, era requisito necesario para la legitimidad de los actos administrativos reguladores de las distintas materias del empleo público. Actualmente, la negociación es libre entre el "antes" (determinación de niveles de negociación y agentes legitimados para negociar) y el "después" (presentación del texto acordado del convenio colectivo al Gobierno), reina la más completa libertad de acción, dentro de los límites y vinculaciones establecidos en la ley. Además, la negociación se puede desarrollar sobre todas aquellas materias que no estén reservadas por la ley, pero no es condición necesaria para las decisiones que se refieran a la organización de los recursos humanos que puedan ser adoptadas unilateralmente (artículo $21.104 \mathrm{CC}$ ), negociadas individual o colectivamente según los casos.

Una vez concluidas las negociaciones, la Agencia transmite a la Presidencia del Consejo de Ministros el proyecto de convenio acordado con los sindicatos y el Gobierno tiene un plazo de quince días para examinarlo, el mismo del que dispone el Tribunal de Cuentas para verificar su viabilidad económica. Si el Gobierno se pronuncia en sentido positivo dentro del plazo o transcurre éste sin pronunciamiento expreso, el convenio se considera autorizado y la Agencia y las delegaciones sindicales proceden a firmar su texto que se publica en la Gaceta Oficial, sin necesidad de norma reglamentaria habilitante.

\section{Interpretación de los convenios}

El artículo 53.1 D.L. 93 prevé que, en el caso de controversias interpretativas de los convenios colectivos, las partes firmantes se reunirán "para definir consensuadamente el significado de la cláusula causante de la controversia". El apartado 3 de este mismo artículo señala que "el acuerdo de interpretación auténtica del convenio tiene efectos sobre las controversias individuales que tienen por objeto las materias reguladas en el mismo acuerdo por aplicación de lo dispuesto en el artículo 2113, apartado cuarto del Código Civil".

Prórroga de la validez o suspensión de la ejecución de los convenios

El artículo 2.1.1 L.D. 92 y 52.3 D.L. 93 prevén específicamente la posibilidad de "prorrogar la ejecución temporal del convenio" o bien de "suspender la ejecución parcial o total en caso de exceder de los limites del gasto". Dice CARINCI que más allá del coste jurídico de la prórroga o suspensión, resultará más elevado el coste político sindical de una tal actuación.

\section{Participación sindical}

Este tema se incluye dentro del título I "Principios Generales" del D.L. 93. El artículo 10 de este texto prevé que las Administraciones Públicas informarán a los representantes sindicales "sobre la calidad del ambiente de trabajo y sobre las medidas inberentes a la gestión de las relaciones de trabajo", además de llegar a la posibilidad de un examen conjunto, a petición suya, sobre las aludidas materias "aunque se mantiene la prevalencia de la decisión definitiva y la responsabilidad de los directivos".

Son muchas las materias en las que las Administraciones Públicas tienen el deber de informar y consultar a las representaciones sindicales; por ejemplo, los criterios generales de organización de las oficinas, en particular los horarios (artículo $16 \mathrm{~d}$ ) D.L. 93), la definición de las plantillas orgánicas (artículo 30.1 D.L. 93), la redistribución del personal en el ámbito provincial (artículo 33.2 D.L. 93), los criterios, modalidades y procedimientos para los traslados voluntarios y de oficio (artículo 35.1 D.L. 93), la fijación del porcentaje de puestos de trabajo a cubrir mediante oposición (artículo 39.1 D.L. 93), etc. 


\section{El reparto de jurisdicción entre el juez ordinario y el administrativo}

Uno de los elementos centrales de la reforma y a la vez más polémicos viene dado por el cambio de jurisdicción. El artículo 12 L.D. 92 dispone que "se autoriza al Gobierno a... confiar los conflictos laborales relativos a los empleados públicos... a la jurisdicción del juez ordinario, de acuerdo con las disposiciones que regulan el proceso laboral, a partir del tercer año consecutivo a la aprobación del Decreto Legislativo". La materia, confirmada en los apartados 1 y 2 del artículo 68 D.L. 93, sólo conoce las excepciones relativas a aquellas cuestiones que son objeto de reserva legal o de actos administrativos de autorización.

El cambio de jurisdicción fue una de las demandas más insistentes de los sindicatos que entendían que el juez administrativo había contribuido a la petrificación de la materia de funcionarios públicos. Antes de la reforma las controversias sobre el empleo público eran de la competencia de la jurisdicción administrativa, concretamente desde 1971, de los Tribunales Administrativos Regionales (TAR). Éstos habían adquirido una competencia específica sobre un sector muy delicado que ocupaba al juez administrativo más de la mitad del trabajo habitual. El propio CASSESE se preguntaba si era oportuno "bacer desaparecer de la escena a un órgano tan experto en la materia". Finalmente, hay consideraciones negativas - falta de reforma de proceso judicial y escasa transparencia del sistema- que han pesado decisivamente en favor del cambio de jurisdicción.

Este cambio de jurisdicción no es inmediato pues la legislación prevé un plazo de espera de tres años, o, de cualquier forma, no antes del cumplimiento de la fase transitoria. El D.L. 93, a su vez, dispone que antes del 30 de junio de 1994, la Presidencia del Gobierno debe presentar al Parlamento un informe sobre la marcha del contencioso a la vista de la reordenación de la Magistratura.

CaRINCI considera esta medida de aplazamiento temporal del traspaso de jurisdicción como prudente, pues de haberse perpetuado la residencia de la materia en sede administrativa, se hubiera corrido el riesgo de falsear el espíritu de la reforma, al estar los jueces administrativos habituados a utilizar otros esquemas jurídicos; de otro lado, el inmediato traslado podría haber causado problemas de colapso en los juzgados ordinarios.

La atribución de las controversias al magistrado ordinario, en funciones de juez del trabajo, viene precedida de un intento de conciliación del empleado con su respectiva Administración, según un procedimiento que puede estar previsto en el convenio colectivo o, en su defecto, regulado por la Administración (artículo 69 D.L. 93).

El artículo 33 del D.L. ํㅜ 546, de 23.12.93, establece el elenco de materias atribuibles al magistrado ordinario en funciones de juez del trabajo y de las que están excluidas materias tales como las oposiciones.
De todos modos, la reforma ha mantenido incólume la jurisdicción a favor del juez administrativo en materias tales como las oposiciones (artículo 217 L.D. 92) lo que, a juicio de CARINCI, no contribuye precisamente a una aplicación lineal de la normativa.

\section{Régimen transitorio}

El artículo 2.1 a) de la L.D. 92 delegaba en el Gobierno la previsión de un régimen transitorio adecuado para asegurar la sustitución gradual del régimen actualmente en vigor en el sector público por el establecido según el presente artículo. El artículo 72.1 D.L. 93 ha resuelto esta previsión, si bien de forma un tanto confusa, al señalar que los acuerdos sindicales ya existentes y las normas generales y especiales reguladoras de la relación laboral de empleo público "integran la regulación de la relación de trabajo a que alude el artículo 2, apartado 2, en la parte no derogada explícita e implicitamente en el presente Decreto". Estas normas dejan de producir efectos desde el momento de la firma de los segundos convenios colectivos.

De forma más expeditiva el artículo 72.2 D.L. 93 establece que "en el contexto de los primeros convenios colectivos... quedan derogadas las disposiciones que prevean automáticamente la influencia en el régimen económico, no tan sólo de las disposiciones que prevean retribuciones económicas complementarias como quiera que sean llamadas a favor de empleados públicos". Se pregunta CARINCI si esta relación significa una prohibición absoluta de todos aquellos conceptos retributivos ligados a la antigüedad. De cualquier forma, el inciso final de este artículo permite salvar las retribuciones fundamentales y complementarias que se disfrutan de naturaleza retributiva ordinaria con carácter de generalidad para cada Administración o ente.

\section{Valoración de la reforma}

La reforma de la relación de empleo público ha recibido, por lo general, las bendiciones de un sector importante de la doctrina (Cassese, Rusciano, Treu, Carinci, Corso, etc.). Estos juicios doctrinales favorables a la reforma contrastan con una reacción más incrédula por parte de la sociedad civil, desilusionada y escéptica ante un sistema político que se ha revelado en los últimos años como corrupto e incapaz de corregirse a sí mismo.

Además de las dificultades políticas derivadas de la difícil coyuntura económica y de la todavía no superada transición política entre la "vieja" y la "nueva" República, la reforma debe enfrentarse a numerosos obstáculos:

- La oposición de numerosos juristas y funcionarios que enfatizan las incertidumbres y contradicciones de los propios textos normativos: al propio Consejo de Estado, al informar el proyecto de ley presentado por el Gobierno, no le dolieron prendas al señalar que una equiparación total del empleo público con el trabajo privado "no parece posible, incluso a la luz de las normas constitucionales sobre la materia (artículos 28, 97, 100, 103 y 113)". 
- La persistencia, como herencia cultural, de prácticas de gestión y conductas sindicales poco responsables y de carácter consociativo.

- La escasez de reformas estructurales capaces de incidir efectivamente sobre la eficacia y la eficiencia en la acción de la Administración Pública.

- La existencia de una abundante normativa, rígida y estratificada, en relación con la cual se ha anunciado recientemente la puesta en marcha de un programa de deslegalización ${ }^{43}$.

- Existencia de una estructura retributiva irracional, oscurantista y poco estimulante.

Ante esta cantidad de obstáculos las previsiones cara al futuro deben ser cautas: el área de empleo público ha iniciado un proceso evolutivo tendente a la convergencia con el empleo privado. Cumplido un año largo desde el lanzamiento de la nueva normativa, ésta se halla aún en fase de rodaje. Hay conciencia de que uno de los puntos neurálgicos sobre los que hay que actuar es la parte organizativa, quizás habría que haber actuado con prioridad sobre ella con respecto al cambio de las relaciones de empleo.

Cierto es que las reformas para navegar precisan de un mar tranquilo y éste no ha sido el caso de Italia en los últimos tiempos. Por ello, quizás la síntesis más cierta sobre el futuro de la reforma sea la que le oí citar a un profesor italiano interviniente en un reciente Seminario Internacional: "En Italia, la reforma de la relación de empleo público va del desastre actual conocido bacia lo desconocido".
- Funcionario del Cuerpo Superior de Administradores Civiles del Estado.

${ }^{1}$ Los dos años transcurridos desde la aparición de la L.D./92 han visto prosperar numerosas medidas e iniciativas encaminadas a completar el diseño de este marco normativo: los Decretos Legislativos "correctivos" 470/93, de 10 de noviembre, y 546/93, de 23 de diciembre; la parte relativa al empleo público en las intervenciones correctivas de la Hacienda Pública (art. 3, Ley 537/93, de 24 de diciembre); la aprobación del reglamento orgánico y de funcionamiento de la Agencia para la representación negocial de las Administraciones Públicas por D.R.P. 144/94, de 25 de enero; la directiva del Departamento de Función Pública sobre funciones y plantillas orgánicas, publicada en la G.U. de 2 de abril de 1994 y los múltiples documentos de reconocimiento, análisis y propuestas referidos a las disposiciones organizativas y del personal publicados en los Cuadernos del Departamento de la Función Pública por iniciativa del Ministro Cassese.

${ }^{2}$ El editorial de La Vanguardia, de 27 de enero de 1993, concluía la información sobre la reforma del empleo público en Italia con esta frase: "(la privatización) no resulta mal espejo para un país como el nuestro, en el que la reforma de la Administración sigue siendo una asignatura pendiente". En relación con la reforma italiana, el único artículo doctrinal publicado en castellano hasta la fecha es el de Miguel SÁNCHEZ MORÓN, "Sobre la reforma administrativa italiana del período de transición, con especial referencia a organización administrativa y al empleo público", publicado en Revista de Administración Pública, mayo-agosto, 1994.

${ }^{3}$ Franco CARINCI "La C.D. Privatizzazione del pubblico impiego", Revista Italiana di Diritto del Lavoro, enero, marzo 1993, pág. 15 a 17.

${ }^{4}$ Luigi DE VITToRio, (CGIL), en dossier sobre "Privatizzazione del pubblico impiego: una riforma dai molteplici obiettivi" en Pubblica Amministrazione oggi, mayo, 1993.

${ }^{5}$ El número de los empleados del Estado (los statali), se ha cuadruplicado en los últimos 70 años, pasando de 540.847 en 1923 a 2.325 .304 en 1992, mientras que la población italiana ha crecido por debajo del $50 \%$ (de 38 millones en 1923 a 57 millones en 1992). El responsable en buena parte de este crecimiento ha sido el boom de los profesores que han aumentado por diez durante el mismo período, pasando de 11.848 en 1923 a 1.037 .806 en 1982. Completan el panorama del "ejército de los empleados del Estado" los empleados civiles y laborales (799.615), los militares (312.606), los magistrados (9.247) y "otro personal" encuadrado en normativas particulares (166.030). Por Ministerios, el más nutrido es el de Instrucción Pública (1.171.000), seguido a larga distancia por Defensa (304.000) e Interior (152.000). Según el anterior Ministro de Función
Pública, Sabino Cassese, estos aumentos de personal se deben a la asunción estable del personal precario en los años 70 y a la multiplicación de figuras anómalas de empleados públicos en los años 80 , expresión, a su vez, del uso de las oficinas públicas como instrumento para ofrecer puestos de trabajo y así poner remedio al malestar de la economía y del mercado de trabajo (Corriere della Sera, 18.2.94).

${ }^{6}$ Una de las características de la Administración italiana es la "meridionalización" de la Función Pública. La mayor parte de los funcionarios (70\%), sobre todo de los niveles más altos, procede de las regiones del sur de Italia, que tienen una cuota de población inferior al 37\%. Las causas de esta situación son dos: en primer lugar, el hecho de que el empleo en la Administración es la principal perspectiva de trabajo para un Sur económicamente débil e incluso subdesarrollado en muchas zonas, sirviendo como instrumento destinado a atenuar las tensiones del mercado de trabajo; en segundo lugar, y por lo que se refiere a las categorías altas, la función pública corresponde al modelo de formación predominante en el Sur, de tipo humanístico (Carreras de Derecho, Ciencias Políticas, Letras). En cuanto a los efectos de esta situación, el primero es el reparto irracional de funcionarios a escala territorial nacional, unido a las presiones de aquellos procedentes del Sur para volver a sus regiones de origen y el segundo, la falta de representatividad social y territorial de esta burocracia en relación con el estado de la población (Carlo D'ORTA y Elisabetta DiamanTI. "La Fonction Publique vers la privatisation". Revue française d'Administration Publique $\mathrm{n}^{\circ}$ 67, juillet-septembre 1993).

${ }^{7}$ En el curso de diez años, de 1980 a 1991, las retribuciones de los empleados públicos italianos han crecido en términos reales el $547 \%$, frente al $4{ }^{\prime} 8 \%$ de los empleados públicos alemanes y al 8'2\% de los franceses, por no considerar la reducción del $52 \%$ experimentada por los funcionarios ingleses (La República. 5.10.92). Este crecimiento de las retribuciones en el sector público lo atribuye TREU a razones de clientelismo político que han incrementado las carreras salariales, alejándolas de todo control, sin un paralelo incremento de la productividad.

${ }^{8} \mathrm{El}$ sector público italiano incluye la casi totalidad de la gran banca, el $50 \%$ de la gran industria, el casi monopolio del transporte aéreo y de los ferrocarriles, autopistas, servicios telefónicos y de correos y diversos monopolios menores de tipo comercial y una presencia dominante en el mundo de la televisión y la radio. La noción empresarial del Estado ha dado vida a media docena de Entes Públicos y grandes grupos, entre ellos el IRI (empresas industriales) ENI (hidrocarburos) y el EFIM (también industrial). En el Gobiemo ha llegado a haber un Ministerio específico para las participaciones estatales. En 1992 se aprobó la Ley de Privatizaciones que posibilitó la transformación de estos grupos empresariales en sociedades por acciones. 
9 Las estadísticas sobre ausencias en la Administración Pública italiana confirman el dato de que el empleado público está ausente del trabajo durante dos meses al año: uno, por permiso ordinario de vacaciones y, otro, por permiso extraordinario, en ambos casos retribuidos. La Ley Financiera de 1994 ha establecido la reducción en un tercio de la retribución a partir del primer día de enfermedad, aplicando un mecanismo similar al de la "franquicia" que es frecuentemente aplicado en el sector de seguros. El anterior Ministro de la Función Pública, Sabino Cassese, ha dictado reglas mediante circular encaminadas a lograr un correcto funcionamiento de las oficinas públicas, como son la instauración de controles automatizados de presencia, la prohibición de trabajos extraordinarios, etc. (La República, 22.2.94). El Gobiemo Berlusconi anunció la total equiparación del periodo de cotización de 35 años necesarios para conseguir la jubilación tanto en el sector público como en el privado y la reducción de la pensión del empleado que se jubilara antes de tiempo en proporción al adelanto. Este anuncio ha suscitado en Italia una oleada de peticiones de jubilaciones anticipadas entre los funcionarios públicos.

${ }^{10}$ Los propios funcionarios italianos no parecen estar tampoco demasiado contentos con la situación. Mientras el $83 \%$ de los funcionarios franceses se declaran satisfechos de su propio trabajo, entre los funcionarios italianos predomina la apatía y la envidia. Una de las causas es la falta de perspectivas en la carrera administrativa. El método más en boga en Italia para progresar en la carrera es el llamado scivolo (podríamos traducirlo como resbalón) o sea el deslizamiento hacia la casilla superior, fuera de los mecanismos normales de concurso, lo que en España llamamos saltar la rejilla. A lo largo de los años 80 se dice que a todos los empleados públicos les ha sido concedida, al menos una vez, la posibilidad de scivolo. Con resultados catastróficos. De hecho es imposible encontrar un ordenanza o un mecanógrafo porque todos aspiran a mayores empeños. La Administración Pública ha llegado a ser un ejército formado sólo por generales.

"Sabino CASSESE: "Le système administratif italien ou l'art de l'arrangement", Revue Française d'Administration Publique, $\mathrm{n}^{2}$ 67, juillet-septembre 1993.

${ }^{12}$ Tiziano Treu, documento fechado en Milán en julio de 1993, repartido en el Seminario sobre La gestión del empleo público. Universidad Internacional Menéndez y Pelayo (Sevilla, 1993).

${ }^{13}$ Carlo D'OrTa y Elisabetta Diamantr. "La fonction publique vers la "privatisation", Revue Française d'Administration Publique, no 67, juillet-septembre 1993.

${ }^{14}$ La definición de la Función Pública italiana como una jungla normativa $y$ retributiva data de los años setenta (Informe Coppo de 1977) y ha adquirido carta de naturaleza. A propósito de esta jungla normativa, dice CASSESE que la materia relativa al personal es una de las más intrincadas debido a la cantidad de normas legislativas, reglamentarias y contractuales que se van entrelazando y superponiendo unas a otras hasta formar una maraña inextricable que cada vez se va embrollando más, por lo que, quien quiera en Italia reconstruir la regulación de cualquier sector administrativo, deberá armarse de mucha paciencia. Prueba evidente de la existencia de esta jungla normativa son las 323 disposiciones dictadas en materia de empleo público entre 1987 y 1990.

Esta misma metáfora de la jungla es trasladable también al campo de las retribuciones. Como dice el sindicalista Trucchi, entre leyes, reglamentos, sentencias, etc., cada nómina en el empleo público es diferente, a pesar de los intentos unificadores de la Ley marco. Una gran parte de este entramado retributivo lo ocupan las denominadas "indemnizaciones" que convierten a las retribuciones de los empleados públicos italianos en un auténtico puzzle. Aunque estas "indemnizaciones" deberían servir sobre el papel para recompensar la productividad, en realidad se atribuyen a piogga con independencia de quien lo merece y quien lo trabaja.

${ }^{15}$ Los directivos del más alto nivel eran designados políticamente, incluso entre personas ajenas a la Administración, mientras que los de nivel inferior eran seleccionados por oposición abierta a candidatos ajenos a la Administración (directivos de empresas, profesiones liberales, universitarios, etc.). D'OrTa y DiamanTI, ob. citada.

${ }^{16}$ M. D'AlBERTI. I dirigenti publici. Il Mulino. Bolonia, 1990.

${ }^{17}$ Franco CARinci, "La C.D. Privatizazione...", op. cit., pág. 9.

${ }^{18}$ El Acuerdo de 23 de julio de 1993 sobre el coste del trabajo suscrito por el Gobiemo, los sindicatos y las empresas y considerado por el nuevo régimen de
Berlusconi como la "estrella polar" ha consensuado acuerdos sobre ámbitos funcionales de negociación, indemnización en caso de falta de renovación contractual (la llamada escala móvil cársica) movilidad de personal para reacomodación de excedentes ociosos, etc. (La República, 21.5.94).

${ }^{19}$ El informe del Grupo de Trabajo sobre contractualización de la relación de empleo público había previsto la excepción a la naturaleza privada de la relación de trabajo del personal dependiente del Estado y de otros órganos públicos en el caso de "esos trabajadores para los cuales la relación orgánica tiene tanto peso que prevalece sobre la del servicio".

${ }^{20}$ Fulvio CORso: "Tipología del personale al servizio della amministrazione italiana", documento repartido en el Seminario sobre La gestión del empleo público. Universidad Intemacional Menéndez y Pelayo (Sevilla, 1993).

${ }^{21}$ El artículo 14 del D.L. 93 atribuye las funciones de dirección política en el ámbito de la Administración del Estado a los Ministros. La Ley $537 / 93$ prevé la posibilidad de que en cada Ministerio haya un Secretario General que sea dirigente y no cargo político.

${ }^{22}$ Carlo D'ORTA. "La riforma della dirigenza: dalla sovrapposizione alla distinzione fra politica e amministrazione?" en Rivista trimestrale di diritto publico 1/1994, página 169 .

${ }^{23}$ Sobre la separación entre política y Administración dice Treu: "Es dificil politica y conceptualmente separar politica y Administración porque la linea de demarcación entre actividad administrativa y decisiones politicas no es siempre nítida... Seria contraproducente reaccionar contra la confusión actual proponiendo una "separación" simplista entre las dos esferas o bien sustrayendo a los políticos decisiones para confiarlas a los administradores técnicos. Las distorsiones de la política actual no se solucionan con la artificial "tecnificación de las decisiones". Para preparar este camino seria necesario desarrollar una investigación sistemática que reduzca la actual "invasión" de la politica en la gestión administrativa sin caer en la desresponsabilización falsamente neutral de la Administración" (T. TREU, documento citado, pág. 6).

${ }^{24}$ Sabino CASSESE: "Il sofisma della privatizazione del pubblico impiego", Corriere Iuridico, 1993, 401 y 407.

${ }^{25}$ Algunas Regiones han entendido que los principios de la reforma sobre dirigenza pública eran lesivos para su propia autonomía, impugnando el artículo 13 del D.L. 93 ante la Corte Constitucional (recurso de la Región de Lombardía 19/93). No obstante, la Sentencia de la Corte Constitucional 359/1993 ha declarado la legitimidad constitucional de la norma impugnada, si bien puntualizando que el Estado tiene el poder de formular principios susceptibles de vincular a la esfera regional, pero no indiscriminadamente, sino en la medida en que tales disposiciones sean susceptibles de expresar por su contenido y por su formulación un principio fundamental y no una norma de detalle (A. ALBANESE, "La riforma della dirigenza pubblica fra organizzacione ministeriale e organizzacione regionale". Le regioni, 4 agosto 1994). Como consecuencia en parte de esta reforma, el Gobierno ha introducido mediante Decreto Legislativo número 470 , de 10 de noviembre de 1993 , dos importantes precisiones sobre la materia: la primera, que lo establecido en el D.L. 93 sólo es válido para aquellas Administraciones cuyos órganos de gobierno son directa o indirectamente expresión de la representación política: Ministerios y Administraciones Autónomas estatales, Regiones, provincias, ayuntamientos (no en los entes públicos, entes de investigación, en la Universidad y en otras Administraciones "no representativas"); la segunda, que las normas del D.L. 93 sobre cualificaciones, cometidos, responsabilidades y selección de los dirigentes han de ser objeto de adecuación por otras Administraciones a sus respectivos ordenamientos en el plazo de seis meses, teniendo en cuenta sus respectivas peculiaridades.

${ }^{26}$ Para la admisión a este curso es necesario estar en posesión del diploma de licenciatura y no haber superado los 35 años de edad, límite que se eleva a 45 para los empleados de carrera de la Administración del Estado que pertenezcan a la ex carrera directiva. El curso dura dos años, seguido de un semestre de formación y aplicación en empresas tanto públicas como privadas. Durante el curso, incluído el período de aplicación, a los participantes les corresponde una bolsa de estudio que paga la Escuela Superior de la Administración Pública.

${ }^{27}$ La disciplina en materia de control de gestión y responsabilidad de los dirigentes, contenida en la versión originaria del D.L. 93 ha sido revisada completamente por el decreto legislativo $n^{9} 470 / 93$. En la definitiva versión del art. 20 del D.L. 93, la norma atribuye el control de gestión indiferentemente a servicios 
de control intemo o a núcleos de valoración, dependiendo su elección de cada Administración Pública, que a tal efecto aprobará los correspondientes reglamentos. Los núcleos de valoración son órganos colegiados de composición mixta, dirigentes generales y expertos, incluso ajenos a la Administración. En cambio, los servicios de control interno son estructuras de corte más tradicional, con un directivo no superior jerárquico del que pueden depender eventualmente otros directivos. Tanto los núcleos de valoración como los servicios de control interno "actúan en posición de autonomía y responden exclusivamente ante los órganos de dirección política" y "dan cuenta trimestralmente de los resultados de la propia actividad a los órganos generales de dirección". Más allá de la determinación de los órganos competentes para el control de la gestión, el D.L. 93, en la versión enmendada por los decretos legislativos, ofrece indicaciones muy importantes también sobre los criterios y la metodología del control que deben ser, tanto cuanto sea posible, estandarizados (Carlo D'ORTA "Controllo di gestione e responsabilitá dirigenziale nelle recenti informe della pubblica amministrazione" en Rivista trimestrale di Scienza dell'Amministrazio$\left.n e, \mathrm{n}^{0} 3,1994\right)$.

${ }^{28}$ Específicamente para los dirigentes generales o equiparados se prevé la jubilación (collocamento a riposo) por razones de servicio, aunque no se haya dispuesto nada con anterioridad sobre la puesta a disposición. Por lo que se refiere a la categoría de dirigentes, loa norma contiene una referencia general a las disposiciones del Código Civil en la materia que permiten entender que se pudiera proceder al despido. Con independencia de estas medidas correctivas, el artículo 2.g) 3 de la L.D. 92 ha previsto también la medida de movilidad en las funciones, pasando por ejemplo de la dirección de una unidad orgánica a funciones de estudio o inspección.

${ }^{29} \mathrm{El}$ artículo 22.2 del D.L. 93 establece que los actuales dirigentes generales y directivos en servicio, a los que no se les haya asignado en la respectiva Administración la dirección de una unidad orgánica o bien competencias de asesoramiento, estudio o investigación serán cargos sin funciones y estarán sometidos a procesos de movilidad que serán regulados mediante Decreto de la Presidencia del Consejo de Ministros.

${ }^{30}$ En realidad, la movilidad voluntaria de los empleados públicos era conocida desde 1988, reglamentada por DPCM no 325, de 5 de agosto de 1988 , y Ley $n^{\circ}$ 554 , de 29 de diciembre de 1988, aunque con escasos resultados. A 31 de diciembre de 1993 se habían puesto a disposición para movilidad 14.933 puestos, de los cuales dos tercios correspondian a las oficinas del norte, tradicionalmente carentes de personal. El número de empleados transferidos a esta misma fecha era de 7.200. Estas transferencias por movilidad voluntaria han quedado, sin embargo, suspendidas a partir de 1 de enero de 1994, a la espera de que se determinen por las Administraciones Públicas las nuevas dotaciones orgánicas mediante la verificación de las cargas funcionales de trabajo.

${ }^{31}$ Italo Rosario PuLi "Il Decreto legislativo 3-2-1993, núm 29, ed. il rapporto di pubblico impiego", L'Amministrazione Italiana, núm 4, 1994, pág. 553.

32 Gianfranco ReBora. "La Modernizzacione del sistema di gestione pubblica. Sviluppo delle risorse umane e privatizzacione del pubblico impiego". Revista Azienda pubblica $\mathrm{n}^{\circ} 2$, agosto 1994 .

${ }^{33}$ Italia ha adoptado desde hace algunos años medidas que tratan de limitar los ingresos en la Función Pública no permitiendo reemplazar más que el $25 \%$ de los funcionarios que se jubilan en las Administraciones Locales y el $10 \%$ en todas las demás Administraciones. Sin embargo, para 1994 se prevé que acce- dan a la Administración mediante oposición 400.000 nuevos empleados públicos (profesores, médicos, carteros, empleados de entes locales) debido a las oposiciones ya programadas o autorizadas en 1993 y al personal incluido dentro de los límites de la reposición (Corriere della Sera, 2 de marzo de 1994).

${ }^{34}$ El artículo 18.2 del Decreto Legislativo número 546, de 11 de diciembre de 1993 , establece excepciones a las oposiciones únicas, concedidas mediante Decreto del Consejo de Ministros autorizando a las Administraciones Públicas a desarrollar directamente oposiciones.

${ }^{35}$ Lineo ZaNGROSSI. "Le mansioni del pubblico impiego dopo l'entrata in vigore del d.lgs. 3.2.1993, n. 29", Comuni d'talia n 11, noviembre 1994.

${ }^{36}$ Treu, documento citado, pág. 8.

${ }^{37}$ El proyecto de Ley Financiera para 1995 prevé la modificación de horarios en las oficinas públicas en el sentido de implantar con carácter general la jornada de tarde (actualmente el horario en las oficinas públicas italianas es de $8 \mathrm{am}$. a $2 \mathrm{pm}$.

${ }^{38}$ TrEU, documento citado, pág. 10.

${ }^{39}$ Según ReBora, si bien las normas diseñan tres niveles de negociación, en la práctica es rara la posibilidad de llegar a un acuerdo marco que sea general para todos los empleados públicos, por lo que lo normal será que los convenios se negocien y estipulen por ámbitos o sectores, algunos de ellos tan numerosos como los que incluye al personal docente, de las Regiones y de los entes locales y de la sanidad (Gianfranco REBORA, conferencia sobre la Función Pública en Italia en las "Jormadas de Análisis de Sistemas de Función Pública", Universidad Carlos III, Getafe (Madrid), 3 de noviembre de 1994.

${ }^{40}$ Por DPR de 1 de diciembre de 1993 han sido nombrados componentes del Comité directivo de la Agencia cuatro profesores universitarios, respectivamente, de Derecho del Trabajo, de Economía Política, de Economía de la Empresa, de Instituciones del Derecho Público y el Director de la Unión Industrial de Torino

${ }^{41}$ Hasta el momento, la Agencia ha recibido dos directrices, una del Ministro Cassese, más completa y detallada y otra del Gobiemo Berlusconi, de carácter más general. La directriz del Gobierno Berlusconi señala que en la negociación colectiva debe tenerse en cuenta que una parte de los complementos económicos han de estar ligados a los resultados y a la productividad, a la vez que fija la necesidad de limpiar, con ocasión de los primeros convenios que se firmen, la "jungla normativa" acumulada a lo largo de estos años, "materia que hay que abordar en la mesa de negociación y que supone un auténtico desafío" (REBORA).

${ }^{42}$ Alfredo CoRPACIO. "Agenzia per la rappresentanza negoziale e autonomia delle pubblique amministrazioni nella regolazione delle condizioni di lavoro", Le regioni, numero 4, agosto 1994.

${ }^{43}$ Giuliano Urbani, Ministro de la Función Pública del Gobiemo Berlusconi, ha incluido la deslegalización entre los seis puntos cualificados de su programa, señalando que Italia tiene actualmente 150.000 en vigor, veinte veces más que Francia o Alemania. Ello significa, a juicio del Ministro, que no se tiene certeza del Derecho y que en un mismo caso dos magistrados pueden aplicar normas distintas, con el resultado de ofrecer al ciudadano un montón de leyes incomprensibles llenas de reenvíos, artículos e incisos de otros textos anteriores (Corriere della Sera, 18-6-94). 